NBER WORKING PAPER SERIES

\title{
EMPLOYER-TO-EMPLOYER FLOWS IN THE UNITED STATES: ESTIMATES USING LINKED EMPLOYER-EMPLOYEE DATA
}

\author{
Melissa Bjelland \\ Bruce Fallick \\ John Haltiwanger \\ Erika McEntarfer \\ Working Paper 13867 \\ http://www.nber.org/papers/w13867
}

\section{NATIONAL BUREAU OF ECONOMIC RESEARCH 1050 Massachusetts Avenue \\ Cambridge, MA 02138}

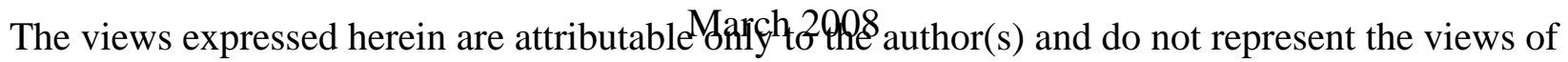
the U.S. Census Bureau, its program sponsors or data providers, or of the Board of Governors of the Federal Reserve System or its staff. This document reports the results of research and analysis undertaken by the U.S. Census Bureau staff. It has undergone a Census Bureau review more limited in scope than that given to official Census Bureau publications. This document is released to inform interested parties of ongoing research and to encourage discussion of work in progress. This research is a part of the U.S. Census Bureau's Longitudinal Employer-Household Dynamics Program (LEHD), which is partially supported by the National Science Foundation Grants SES-9978093 and SES-0427889 to Cornell University (Cornell Institute for Social and Economic Research), the National Institute on Aging Grant R01 AG018854, and the Alfred P. Sloan Foundation. Some or all of the data used in this paper are confidential data from the LEHD Program. The U.S. Census Bureau supports external researchers' use of these data through the Research Data Centers (see www.ces.census.gov). For other questions regarding the data, please contact Jeremy S. Wu, Manager, U.S. Census Bureau, LEHD Program, Demographic Surveys Division, FOB 3, Room 2138, 4700 Silver Hill Rd., Suitland, MD 20233, USA. (Jeremy.S.Wu@ @ census.gov) The views expressed herein are those of the author(s) and do not necessarily reflect the views of the National Bureau of Economic Research.

NBER working papers are circulated for discussion and comment purposes. They have not been peerreviewed or been subject to the review by the NBER Board of Directors that accompanies official NBER publications.

(C) 2008 by Melissa Bjelland, Bruce Fallick, John Haltiwanger, and Erika McEntarfer. All rights reserved. Short sections of text, not to exceed two paragraphs, may be quoted without explicit permission provided that full credit, including $\odot$ notice, is given to the source. 
Employer-to-Employer Flows in the United States: Estimates Using Linked Employer-Employee

Data

Melissa Bjelland, Bruce Fallick, John Haltiwanger, and Erika McEntarfer

NBER Working Paper No. 13867

March 2008

JEL No. E24,J62,J63

\begin{abstract}
We use administrative data linking workers and firms to study employer-to-employer flows. After discussing how to identify such flows in quarterly data, we investigate their basic empirical patterns. We find that the pace of employer-to-employer flows is high, representing about 4 percent of employment and 30 percent of separations each quarter. The pace of employer-to-employer flows is highly procyclical, and varies systematically across worker, job and employer characteristics. Our findings regarding job tenure and earnings dynamics suggest that for those workers moving directly to new jobs, the new jobs are generally better jobs; however, this pattern is highly procyclical. There are rich patterns in terms of origin and destination of industries. We find somewhat surprisingly that more than half of the workers making employer-to-employer transitions switch even broadly-defined industries (NAICS super-sectors).
\end{abstract}

Melissa Bjelland

U.S. Census Bureau

LEHD

Room 2138, Building 3

4700 Silver Hill Road

Suitland, MD 20746

melissa.bjelland@ey.com

Bruce Fallick

Federal Reserve Board

Washington, DC 20551

bruce.fallick@frb.gov
John Haltiwanger

Department of Economics

University of Maryland

College Park, MD 20742

and NBER

haltiwan@econ.umd.edu

Erika McEntarfer

U.S. Census Bureau

LEHD

4700 Silver Hill Road

Suitland, MD 20746

erika.l.mcentarfer@census.gov 


\section{Introduction}

An enormous amount of worker and job reallocation continually takes place in the U.S. economy. For example, Davis, Faberman and Haltiwanger (2006) (hereafter DFH) report that the quarterly job creation and destruction rates each average around 6 to 8 percent of total employment and that accession and separation rates are 2-3 times as large. ${ }^{6}$ Job reallocation induces worker reallocation with less profitable firms shedding jobs and thus workers and more productive firms adding them. Much of the observed job reallocation occurs within narrowly defined sectors, so the primary drivers of the continual reallocation of jobs evidently include idiosyncratic shocks to technology, demand and costs. The pace of job reallocation does, however, fluctuate both secularly and cyclically, and as such is related both to the overall pace of technological change and to macroeconomic shocks. In addition to these job dynamics, workers also continuously sort themselves over a given distribution of jobs. Workers switch jobs and change employment status because of "supply-side” events such as labor force entry, family relocation and retirement, or for reasons of career development, better pay and preferable working conditions.

There is a large and growing empirical and theoretical literature quantifying and studying these worker and job flows and their interactions with the outcomes of firms and workers. The U.S. statistical agencies now have a variety of data products -- e.g., the Business Employment Dynamics (BED) and the Job Openings and Labor Turnover Survey (JOLTS) programs at BLS and the Longitudinal Business Database (LBD) and Longitudinal Employer Household Dynamics program (LEHD) programs at the Census Bureau -- that tabulate these flows by a variety of worker and firm characteristics. Given the huge volume of these flows and the inherent frictions involved in the reallocation of jobs and workers, there is considerable interest in understanding the nature and implications of these frictions at the micro and aggregate level. One important element largely missing from the expanding measurement of worker and job flows is the flows of workers in a time period directly from one employer to another. The

6 See Table 1, Davis, Faberman and Haltiwanger (2006) that draws upon JOLTS, BED and LEHD statistics to quantify job and worker flow rates. There are many studies of these worker and job flow rates including Davis, Haltiwanger and Schuh (1996), Acs, Armington and Robb (1999), Burgess, Lane and Stevens (2000). 
measurement and analysis of employer-to-employer flows sheds light on how the frictions in the labor market are being resolved over time, across sectors, and across different types of firms and workers. Such direct employer-to-employer flows are not without frictions, but by construction they reflect flows that do not involve a period of frictional unemployment.

Quantifying and studying employer-to-employer flows is of interest not only because of what it tells us about frictions in the labor market, but also because employer-to-employer flows include origin and destination information about the employers. It is of interest to know about origin and destination of transitions for workers of different characteristics (age, gender, education, ethnic and foreign born status). It is also of interest to know how earnings change with such transitions, and origin-destination information permits measurement of earnings changes.

In this paper, we use the recently developed longitudinal linked employer-employee data from the LEHD program at Census Bureau to measure and study employer-to-employer flows. These data are exceptionally well suited to an examination of quarterly worker flows as they trace the job histories of a large proportion of employed individuals over several years. As we discuss in section II, the long histories of workers as well as the rich set of employer characteristics yield advantages over related measurement of employer-to-employer flows from the CPS (see Fallick and Fleishman 2001 and 2004). The CPS based flows have alternative advantages, as we also discuss in section II, so we regard these measurement efforts as complementary.

Our main findings are as follows. First, we find that the flow of workers from employer to employer is large and is an important component of overall worker flows. Using our preferred measurement method, we find that quarterly employer-to-employer flows account for about $3.9 \%$ percent of employment on average and $29 \%$ percent of main job separations. These patterns vary systematically over time - with interesting secular, seasonal, and cyclical variation. We find that employer-to-employer flows are procyclical, rising throughout the late 1990s and falling sharply in 2001. We also find that the pace of employer-to-employer flows as a fraction of employment and separations has remained low in the post-2001 period following the 
recession. This latter finding is consistent with related findings in the recent literature of a declining pace of worker and job flows in the U.S. economy in the post-2000 period (see DFH).

The pace of employer-to-employer flows varies systematically by worker, job and firm characteristics. For workers, employer-to-employer flows as a fraction of employment and separations declines with age through the mid 60s and then flattens out -- the decline with age as a fraction of separations is especially rapid in the age range 50-65 when retirements presumably become a more important form of separation than employer-to-employer transitions. We find that less educated workers have a higher pace of employer-to-employer flows as a fraction of employment but there is no discernable pattern by education as a fraction of separations. The pattern by education reflects the higher overall rate of worker flows of less educated but conditional on a separation, education is not an important factor.

Employer-to-employer (henceforth E-to-E) flows are somewhat concentrated among frequent job changers, and even more so among the employees of high-turnover firms. Firms in the highest quintile of turnover -- those where more than $6.6 \%$ of workers experience an E-to-E flow in an average quarter -- account for over $60 \%$ of total E-to-E flows. Concentration of E-toE flows among highly mobile workers is less pronounced but still in evidence - over $50 \%$ of total E-to-E flows in a representative quarter are from workers who changed jobs at least twice in the previous three years. Yet fully $20 \%$ of employer-to-employer flows in a given year involve workers separating from a job held for more than two years.

Our findings regarding job tenure and earnings dynamics suggest that for those workers moving directly to new jobs, the new jobs are generally better jobs, and that moving directly to a better job is easier in boom than a bust. Tenure at new jobs is generally longer than at separating jobs, with $25 \%$ of destination job matches lasting more than two years. We find that on average workers who make employer-to-employer transitions see large increases in earnings. However, this pattern is highly procyclical. The average worker making a direct employer-to-employer transition in a recession sees a smaller increase in earnings than a worker making such a transition in a boom. This hit on earnings gains for making a transition during a recession is especially large for younger workers. We also find larger quarterly growth in earnings for 
workers making employer-to-employer transitions than workers who remain in their same job. This latter pattern holds for all quarters and age groups we observe.

There are rich patterns in terms of origin and destination of industries. We find, to our surprise, that a very large fraction of the workers making employer-to-employer transitions switch even broadly defined industries. More than half of workers making an employer-toemployer transition switch NAICS super-sectors. Some of this finding is explained by looking at the details of the origin and destination sectors. For example, for workers employed in the software publishing industry we find that just over $1 / 4$ of the workers making an employer-toemployer transition remain in software publishing. However, the destination industries reflect closely related activities, such as Custom Computer Programming Services, Computer Systems Design Services and Semiconductor Manufacturing.

The paper proceeds as follows. Section II discusses the LEHD data infrastructure and its suitability for measuring employer-to-employer flows. Section III describes the measurement methodology for measuring employer-to-employer flows in the LEHD data. Section IV presents the main empirical findings and Section $\mathrm{V}$ has concluding remarks.

\section{Advantages of Using LEHD Data to Estimate Employer-to Employer Flows}

Recent research on employer-to-employer flows in the United States exploited the dependent interviewing techniques used in the Current Population Survey (CPS) to provide nationally representative estimates of high-frequency flows of workers between employers. Fallick and Fleischman (2004) estimated that 2.6\% of employed persons change employers each month, and that employer-to-employer flows fell markedly during the recession that began in 2001. The CPS has several advantages for estimating E-to-E flows of workers. The CPS is already the primary source of the data on flows of workers across labor market states, so the estimated E-to-E flows can be joined consistently with the other flows in generating a more complete picture of labor market dynamics. The CPS sample is representative of the entire civilian noninstitutional population in that it is not limited to particular cohorts, household members, or sectors. The data measures flows at a monthly frequency, and so is likely to capture 
movements from one employer to another that do not involve a significant period of nonemployment. And, of course, the CPS contains a rich set of demographic and other information on individuals. ${ }^{7}$

However, the CPS also has several important limitations. The size of its sample, while large for a survey of households, remains small for some purposes. The representativeness of the CPS is compromised by significant attrition, especially because, by design, it does not follow workers when they change residences. The CPS follows individuals for only four consecutive months, so long employment histories cannot be constructed. As a household survey, it relies on the responses of individuals or other members of their households. And the survey design is such that it can be used to measure flows only between a worker's main jobs. The CPS also measures worker flows from only one side of the market: the worker's side.

The LEHD data offer several advantages for estimating the magnitude of job-to-job flows. First, the LEHD is based on comprehensive administrative data covering a large fraction of the U.S. workforce. This makes possible analysis of flows of workers across detailed industries, detailed demographic groups, and even flows of workers following specific regional economic shocks. In particular, the universe of the LEHD data is employment covered by the state unemployment insurance (UI) system. State unemployment insurance system coverage is broad and basically comparable from state to state. Covered employment generally includes all employees of firms within a state with some notable exceptions. ${ }^{8}$ UI and associated ES-202 data are provided to the Census Bureau by over 40 participating state partners. These data are supplemented with Census demographic data, providing worker characteristics such as age, race, and gender.

Second, unlike the CPS, which follows individuals for only four consecutive months, the longitudinal nature of the LEHD data means individual work histories can be followed

\footnotetext{
${ }^{7}$ See Fallick and Fleischman for a more complete description of the CPS data and the merits of the CPS relative to other previously available data sources.

8 Workers not covered by the state unemployment system include many agricultural workers, independent contractors, some religious and charitable organizations, the self-employed, some state government workers, and employees of the federal government (who are covered under a separate insurance system). For detailed information
} 
continuously for years. This is important as it allows us to examine the extent to which gross job-to-job flows in the U.S. economy are driven by a small but mobile segment of the workforce. The LEHD data follows workers across employers as long as they continue to collect UIcovered wages, and follows workers who change residence so long as they continue to work in one of the over 40 states participating in the program. ${ }^{9}$

Lastly perhaps the most unique aspect of the LEHD data is the presence of the link between the worker and the employer. The longitudinal nature of the linked data on both the individual and business side allow us to track the flows of workers between a large sample of firms in the U.S. economy, while also identifying workers' employment histories and the dynamics of the firms across which workers are being redistributed. This link allows us to determine to what extent flows between employers are driven by the dynamics of the employers themselves. For instance, we can examine to what extent are employer-to-employer flows concentrated among employees in high turnover firms. Or to what extent flows are driven by job creation at destination firms, or job destruction at separating firms.

The LEHD data do have a few disadvantages in identifying employer-to-employer flows. There is some potential to miss employer-to-employer transitions that involve cross-state migrations in employment. Employment in the federal government, unincorporated selfemployment, religious and charitable organizations, and certain agricultural enterprises are not covered. ${ }^{10}$ Most fundamentally, the LEHD data do not measure employment at a point in time. The unemployment insurance records that underlie the data report only quarterly earnings. They contain no information regarding how many hours or weeks were worked within the quarter- or which weeks were worked if the worker was at the firm for less than a full quarter. In addition to limiting the analysis to quarterly frequency, this presents some problems in distinguishing between true E-to-E flows and multiple-job-holding, and in determining the direction of some employer-to-employer flows in the presence of short-duration jobs. These are not insignificant problems given that short-job to short-job flows account for a substantial fraction of employer-

on UI covered employment see Stevens (2000) and The BLS Handbook of Methods.

9 In the current study, however, we will not follow workers across state lines.

10 Although it is useful to note that the LEHD program has ongoing plans to add Federal workers and self-employed 
to-employer flows. We will discuss in detail how we deal with this feature of the data in the next section.

Golan, Lane, and McEntarfer (2006) used LEHD data to examine annual flows of significantly attached workers between employers within and across industries. They found that $25 \%$ of workers who demonstrated some attachment to their employer changed jobs in a given year, split almost evenly between industry stayers and industry changers. As the focus of the current paper is to estimate the quarterly frequency of employer-to-employer flows in both main and secondary jobs, our methodology differs from theirs. The next section explains in greater detail the methodology we use estimate the quarterly flows of workers between employers in the LEHD data.

Before proceeding to the measurement methodology and the estimates of the employerto-employer flows, we note that the underlying source data for all of the statistics reported in this paper are administrative data that provide universal coverage of workers in covered sectors. Unlike estimates of employer-to-employer flows from survey data (e.g., the CPS), with about 6-7 million jobs and 200,000 to 360,000 employer-to-employer flows observed each quarter there is no significant sampling error in our estimates and we report no sampling error statistics. There may of course be measurement error from a variety of sources (e.g., measurement error in longitudinal identifiers or industrial classification for employers or reported earnings for workers) that impact the reliability of these estimates but such error reflects non-sampling error. A comprehensive description of the LEHD data infrastructure files, the measurement methodology and in turn the possible sources of nonsampling error is provided in Abowd et. al. (2006). In the current paper, only descriptive statistics of the employer-to-employer flows are provided with little or no statistical analysis of hypotheses about the causes and consequences of employer-to-employer flows.

\section{Defining Employer-to-Employer Flows in LEHD data}

workers. 
The quarterly nature of the LEHD data presents some unique methodological issues with regard to measuring job-to-job flows. As mentioned in the previous section, the unemployment insurance records that underlie the data do not measure employment at a point in time, but only report quarterly earnings. They contain no information regarding which weeks during the quarter the worker was employed or how many hours or weeks she worked within the quarter. Table 1 below provides a hypothetical example of wage history data, in this case the quarterly wage histories for two individuals who were each employed with two different employers during the year.

Our goal is to characterize quarterly job transitions, including those involving shorter jobs or secondary jobs. We begin by defining the existence of a job match in quarter $t$ if worker $i$ has positive earnings from employer $j$ in that period (denoted $m_{i j t}=1$ ). Matches in only one of two consecutive quarters indicate that either an accession or separation has occurred. That is, workers with positive earnings in one period but none in the subsequent period are assumed to have separated from their employers at some point during the quarter with positive earnings. Similarly, individuals who are observed to move from receiving no earnings from a firm to earning a positive amount are assumed to have acceded to the employer sometime during the quarter with positive earnings. In Table 1, we would say that Person 2 separated from Employer $\mathrm{B}$ and acceded to Employer Z during quarter 2. Formally, we define accessions and separations as follows:

(1) Accessions $\left(\mathrm{a}_{1}\right)$ : individual $i$ acceded to employer $j$ during quarter $t$

$$
a_{1 i j t}=\left\{\begin{array}{l}
1 \text { if } m_{i j t-1}=0 \& m_{i j t}=1 \\
0 \text { otherwise }
\end{array}\right.
$$

(2) Separations ( $\left.\mathrm{s}_{1}\right)$ : individual $i$ separated from $j$ during $t$

$$
s_{1 i j t}=\left\{\begin{array}{l}
1 \text { if } m_{i j t}=1 \& m_{i j t+1}=0 \\
0 \text { otherwise }
\end{array}\right.
$$


where $m_{i j t}=1$ if worker $i$ had positive earnings at employer $j$ in quarter $t$, and $m_{i j t}=0$ otherwise.

If we define an employer-to-employer flow simply as an accession to a new employer $k$ that occurs in the same quarter as that same worker separated from employer $j$, we have the following definition of an employer-to-employer flow: ${ }^{11}$

(3) Flow Employer-to-Employer Transition $\left(E E m_{i j k t}\right)$ : individual $i$ transitions from firm $j$ and to firm $k$ during $t$ :

$$
E E m_{i j k t}=\left\{\begin{array}{l}
1 \text { if } s_{1 i j t}=1 \& a_{1 i k t}=1 \\
0 \text { otherwise }
\end{array}\right.
$$

where $s_{1 i j t}$ and $a_{1 i k t}$ are defined as above.

A limitation of the definition in (3) is that in the case of matches that appear in only one quarter, we cannot distinguish with any confidence between an employer-to-employer flow and multiple job holding. For instance, imagine a work history such that of Person 1 in Table 1. Although Person 1 would be defined as experiencing an employer-to-employer flow in the second quarter according to the definition (EEm) in equation (3), it is also possible that Person 1 held jobs at firm A and firm Q simultaneously. The inclusion of multiple job holding in this measure is likely to result in an over-counting of employer-to-employer flows. Another problem with one-quarter jobs is that, even if we treat them as representing an E-to-E flow, it is difficult

11 While valid E-to-E flows might include situations in which a person separates from one employer in quarter $t$ and accedes to a different employer in quarter $t+1$, we choose not to count these transitions. For the purposes of our current study, we are interested in flows that do not involve a significant period of intervening nonemployment. As noted above, we know only each individuals earnings from a given employer for the entire quarter. Thus, we know whether an individual worked for a given employer during the quarter, but we do not know which weeks during the quarter the match was in effect. A typical quarter contains thirteen weeks. If the timings of the separation in one quarter and of the accession in the subsequent quarter are independent of each other and each is uniformly distributed within the quarter, then the mean duration between the two employers is thirteen weeks, which is longer than we would like to count for an E-to-E transition. Therefore, we restrict our present analysis to employer-to-employer flows that occur within a single quarter, that is, to flows where the separation and accession, as defined above, occur in the same quarter. While it is possible to have a short nonemployment spell during an employer-to-employer flow that occurs within the quarter, it is unlikely to be a spell of more than a month in length. (Again assuming uniform distributions, the mean duration is about four weeks.) We leave an analysis of flows into and out of longer spells of non-employment for future work. 
to decide which is the origin job and which is the destination job. Preliminary estimates of E-toE rates using the EEm measure in LEHD data found rates as high as $16 \%$ using this measure. This seems an improbably high rate of job-to-job flows and thus, this measure is likely overcounting the true number of flows.

For these reasons, for most of our analysis we use a more restrictive definition of employer-to-employer flows that requires that two quarters of positive earnings be observed both at the separating and the acceding employer. Formally,

(4) Consecutive-Quarter Employer-to-Employer Transition $\left(E E b_{i j k t}\right)$ : individual $i$ transitions from firm $j$ and to firm $k$ during $t$ :

$$
\begin{gathered}
E E b_{i j k t}= \\
\left\{\begin{array}{l}
1 \text { if } s_{2 i j t}=1 \& a_{2 i k t}=1 \\
0 \text { otherwise }
\end{array}\right.
\end{gathered}
$$

where $s_{2 i j t}=1$ if $s_{1 i j t}=1$ and $m_{i j t-1}=1$ and $a_{2 i k t}=1$ if $a_{1 i k t}=1$ and $m_{i k t+1}=1$.

Here we use consecutive quarters of earnings to construct an estimate of point in time employment. If a worker has positive earnings at an employer in both quarter $\mathrm{t}-1$ and quarter $\mathrm{t}$, we can say with reasonable confidence that he was an employee of that firm on the first day of quarter $\mathrm{t}$ (as well as the last day of quarter t-1). Thus the restrictions we add here amount to (a) the worker must be employed at the separating job on the first day of the relevant quarter, and (b) the worker must be employed at the acceding job on the last day of the relevant quarter, with both the separation and the accession occurring during the quarter. ${ }^{12}$ The additional attachment restriction in EEb compared to EEm provides greater confidence that the transition we have identified is, in fact, an employer-to-employer flow, as well as making clear the direction of this flow. Of course, the greater clarity comes at the cost of excluding some employer-to-employer flows that include very short jobs, so this definition may underestimate the true magnitude of employer-to-employer flows.

12 In the example in Table 1, Person 2 experiences a consecutive-quarter employer-to-employer flow in the second quarter from firm B to firm Z. 
One can go farther in this direction to restrict attention to jobs that more clearly have some traction to them. In this spirit we also examine a definition of E-to-E flows that includes only jobs that we can tell last for at least one full quarter, which, in our quarterly data, means that positive earnings in the match were observed in three consecutive quarters. That is, we can infer that individual $i$ worked for firm $j$ for the entirety of quarter $t$ if $m_{i j t-1}=1, m_{i j t}=1$, and $m_{i j t+1}=1$. Full-quarter E-to-E flows are then defined as flows in $t$ from one full-quarter job in $t-1$ to another full-quarter job in $t+1$. More formally:

(5) Full-Quarter Employer-to-Employer Transition ( $\left.E E f_{i j k t}\right)$ individual $i$ transitions from firm $j$ and to firm $k$ during $t$ :

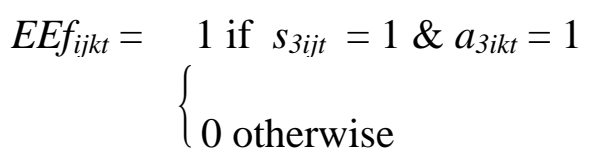

where $s_{3 i j t}=1$ if $s_{2 i j t}=1$ and $m_{i j t-2}=1$ and $a_{3 i k t}=1$ if $a_{2 i k t}=1$ and $m_{i k t+2}=1$.

This definition excludes a greater number of true E-to-E transitions involving short-term jobs than does the EEb definition. This may be an advantage or a disadvantage depending on the question and the population under consideration, but we expect the EEf definition to understate the overall number of E-to-E flows. This measure does have the advantage of allowing us to better examine earnings transitions associated with flows between employers, because we observe a full quarter of earnings at both the origin and the destination jobs. We will use fullquarter flows mainly when estimating earnings growth associated with flows from employer to employer.

Applying these definitions is straightforward if a person experiences no more than one separation and no more than one accession each quarter. However, the application is more complicated if a person experiences multiple separations or accessions in a quarter such that more than one pair of jobs would fit the definition of an E-to-E flow. For purposes of counting the number of E-to-E transitions, we impose the rule that a given separation or accession can contribute to only one E-to-E transition. Even so, for more general purposes there remains the 
problem of pairing the separations with the accessions so as to identify the origin and destination job in each transition. We would like to pair origin and destination jobs that play similar roles in the worker's career, those that the worker herself would identify as replacing each other. To take an extreme example, we would not like to pair a separation from a full-time job with an accession to a part-time weekend job, if more equal pairings are possible. ${ }^{13}$

Given the limited information at our disposal, we do this by pairing jobs with the most similar relative earnings. Lacking data on the number of hours or weeks worked during a quarter, we recognize that the relative earnings of jobs in a single quarter can be influenced by when during the quarter each job began or ended, and by transitory fluctuations in hours worked. In order to minimize these influences, we compare earnings-weighted average quarterly earnings. ${ }^{14}$ When there exist multiple job separations or job accessions for a worker in a particular quarter, we take the separating job with the greatest average earnings over the previous four quarters and match it to the accession with the greatest average earnings in the subsequent four quarters. We refer to this match as the 'primary' employer-to-employer flow in a quarter. If after pairing the separation and accession with the greatest earnings there remains another unmatched separation/accession pair, the separation and accession with the next highest earnings are matched. And so on until there is no potential accession/separation pair that matches the job attachment criteria for the particular flows measure. As it happens, multiple E-to-E flows in a quarter are fairly rare, generally less than $0.5 \%$ of flows in any quarter.

A related issue is identifying the importance of the separating and acceding jobs to the person's career. For example, we would like to differentiate between transitions from a main job to another main job versus transitions involving secondary jobs. To do this, we compare earnings weighted average earnings in the previous four quarters for separating jobs to those in all other jobs (both separating and otherwise) in that same period; the job with the highest average earnings we define as a main job. We do the same for acceding jobs, looking forward

13 If course, even with only one separation and one accession in a quarter, we may observe E-to-E flows that have this unequal nature.

14 More specifically, we rank all separating jobs by the earnings weighted average earnings over the period t-3 to t, $\left(\sum_{\mathrm{t}-3}^{\mathrm{t}} \mathrm{W}_{\mathrm{ijt}}{ }^{2}\right) / 4$. We then rank all accessions by earnings weighted average earnings over the period $\mathrm{t}$ to $\mathrm{t}+3$, $\left(\sum_{\mathrm{t}}^{\mathrm{t}+3} \mathrm{~W}_{\mathrm{ijt}}{ }^{2}\right) / 4$. We then pair the highest ranked separating job with the highest ranked acceding job. 
four quarters. Employer-to-employer flows involving main jobs as both the origin and destination job we define as 'main-to-main' job flows. About 96\% of E-to-E flows in an average quarter of our sample are main job to main job flows by this definition.

\section{Empirical Patterns of E-to-E Flows}

For the current analysis, we construct a 13-year panel of linked employer-employee data by pooling the wage histories of three large LEHD states that have data from 1991-2003. ${ }^{15}$ We include in our sample both male and female workers, age 15-99, although we break out much of our subsequent analysis by age groups. We impose no earnings restrictions other than those discussed in the previous methodology section requiring positive earnings to identify employment at the firm. We have calculated transitions only within each state; transitions from an employer located in one state to an employer located in another state are lost. None of the selected states have a large metropolitan areas at the border of the state that would be conducive to a large number of cross-state transitions. ${ }^{16}$

\section{A. The overall size of E-to-E flows}

Table 2 summarizes the magnitude of employer-to-employer flows in LEHD data, using both our primary flows measure (EEb) as well as our more restrictive measure (EEf). First we will discuss the results for our primary EEb flows measure. Overall, we find that $3.9 \%$ of jobs held on the first day of the quarter experience a separation from that job and an accession to a new employer during the quarter. Using employment as a denominator instead of jobs, the figure is very similar: $4.1 \%$ of persons employed on the first day of the quarter separate from an employer during the quarter and are employed at the new job on the last day of the quarter. As a percentage of separations, $27 \%$ of workers separating from jobs during the quarter have a new

15 The earliest quarter of available LEHD data varies somewhat by participating state, with many states having data series that start in 1990 or 1991, and almost all states having data from 1998 forward.

16 We limited the current study to three illustrative states and to within-state movements in order to reduce the substantial computational burden of the analysis. The long run objective is to make these employer-to-employer flows part of the Quarterly Workforce Indicators (QWI) of the LEHD program so that these statistics would be available for all states and would also incorporate cross-state movements yielding E-to-E flows. 
employer on the last day of that quarter. This is a significant amount of job reallocation occurring in the economy in any given quarter. Note that while our estimate of a $4 \%$ quarterly E-to-E rate is somewhat lower than the quarterly employer-to-employer transition rate implied by the $2.6 \%$ monthly E-to-E rate Fallick and Fleischman found in the CPS, it is much closer than the very high rate we found in our preliminary analysis of EEm flows, which likely included instances of multiple job holding. This gives us greater confidence in using EEb as our primary E-to-E flow measure.

Table 2 also summarizes the magnitude of flows for the more restrictive EEf flows measure. The EEf measure restricts itself to longer jobs -- those that last at least one quarter. We find that $2.2 \%$ of jobs held for all of the previous quarter experience a separation from that job and an accession to a new job that lasts at least one quarter. This is lower than the transition rate that includes shorter jobs, not surprisingly. This is partly due to the lower separation rate from longer jobs but also due to the lower percentage of full-quarter separations that involve an EEf flow. Only 20\% of separations from jobs held at least one quarter are to a new job held at least one quarter. Although this restriction is interesting for some purposes, particularly the analysis of employer-to-employer transitions involving longer jobs, our primary purpose for introducing it is to utilize the full quarter of earnings at separating and acceding jobs to have an apples-to-apples comparison for measuring earnings changes. We will not impose it until we come to discuss the earnings changes associated with E-to-E transitions.

Table 3 breaks out employer-to-employer transitions by whether the flows involve main or secondary jobs. ${ }^{17}$ Most jobs in our data are main jobs, with only 5.9\% of workers in our data holding multiple jobs on the first day of a given quarter. The overwhelming majority of our Eto-E flows are flows from one main job to another (96\%). Our estimate of the E-to-E rate for main jobs, 3.9\%, is similar to that for all jobs. We would expect that most workers would be less likely to leave their main jobs voluntarily without another job already lined up or particularly good prospects, than they would be to leave a secondary job under such circumstances, and our

17 We define as a main job the job held on the first day of the quarter that has the greatest earnings weighted average earnings over the previous four quarters (see section III for the discussion of our earnings ranking algorithm). To define destination main jobs we use the job held on the last day of the quarter with the greatest 
results confirm this. We find that separations are less common from main jobs (13\%) than from secondary jobs (31\%), and that separations from main jobs are much more likely to result in a flow to another employer (29\%) than separations from secondary jobs (8\%).

The E-to-E flow rates derived from the CPS by Fallick and Fleischman, mentioned above, are based on comparisons of main jobs from one month to the next. The main job measures in Table 3 should therefore be more comparable to the CPS definition. Our estimate of a 3.9\% quarterly E-to-E rate is lower than three times the $2.6 \%$ monthly E-to-E rate Fallick and Fleischman found in the CPS. There are several reasons that estimates of E-to-E flows may differ between the LEHD and the CPS. First, our definition of the main job, based on an explicit ranking by earnings, need not match the subjective concept of a main job used in the CPS. However, the similarity of our estimates of E-to-E flow with and without the restriction to main jobs suggests that this does not explain much of the discrepancy. Probably more important are differences between a monthly point-in-time measure of employment as in the CPS and the quarterly earnings measures developed with the LEHD. In particular, the requirement in our preferred definition that separating jobs are held on the first day of the quarter and acceding jobs are held on the last day of the quarter eliminates many E-to-E flows involving very shortduration jobs.18 Other differences between the CPS and our LEHD pooled state sample will result in differences between the two estimates. First, as noted at the outset, the figures reported here from the LEHD represent only 3 states. Second, the two sources differ in scope (for example, the CPS includes the unincorporated self-employed). Third, the sample periods do not match exactly (1992-2002 vs. 1994 to 2003). Nevertheless, despite these differences in data and methodology, the two sources yield estimates that are roughly comparable in magnitude when it

earnings weighted average earnings over the subsequent four quarters.

18 One issue here is multiple transitions within the quarter. Suppose that both the monthly and quarterly data were point-in-time measured at the same point in the month. Say that the monthly rate of E-to-E transitions (CPS definition) is $\mathrm{X}$, and a fraction $\mathrm{Y}$ of all persons who make a monthly E-to-E transition make another monthly E-to-E transition during the quarter. Then the rate of quarterly E-to-E transitions is not $3 * X$; it is $\left(3-2^{*} \mathrm{Y}\right) * \mathrm{X}$. If this were the only issue, then, the figure from the CPS and that from the LEHD would be perfectly reconciled if $3 / 4$ of all monthly E-to-E transitions were made by individuals who make another monthly E-to-E transition within the quarter. In fact the evidence from the CPS suggests that the fraction $Y$ is only about $8 \%$. In contrast, below we show that a touch more than $1 / 2$ of quarterly E-to-E transitions are made by individuals who make another E-to-E move within the year. 
comes to the importance of E-to-E flows, with Fallick and Fleischman finding that E-to-E transitions constitute 39\% of main job separations, compared to the $29 \%$ figure in our data.

\section{B. Fluctuations and Trends in E-to-E transitions.}

Figures 1 and 2 show our estimates of how the quarterly E-to-E rate has changed over time between 1992 and 2003. The popular perception is that United States has become an ever more transient labor market, wherein workers change jobs more often, both from choice and necessity, and contingent work arrangements have become more common. As background, in the states in our study, overall labor market transitions -- both the rates of separation and of accession -- rose slightly during the 1990s and fell beginning in 2001. Similarly, as discussed in DFH, the BED data shows that job creation and job destruction both increased slightly over the expansion of the 1990s and fell during the recession, with some recovery having begun only in since 2003. In addition, DFH show that unemployment inflows and outflows (measured from the CPS) also exhibit a declining trend over this period. These patterns of worker, job and unemployment flows suggest if anything a declining trend in the pace of churning of workers and jobs over the last 15 years or so.

E-to-E flows provide a unique measure of churning since this flow inherently reflects both sides of the separations/accessions accounts. What we see, whether looking at E-to-E transitions as a fraction of employment or as a fraction of separations, is that E-to-E rates rose from 1992 to 2000, fell dramatically in 2001, and stabilized in 2002 and 2003 at a lower level than in the 1990s. We find that the correlation between the underlying net growth rate of employment (for the states we use for this analysis) and the E-to-E flows is strongly positive - at an annual frequency the correlation is 0.82 (with a standard error of 0.006).19 While this is just one cyclical episode, it is nevertheless striking that employer-to-employer transitions are so cyclically sensitive. Unfortunately, our data stop just as the labor market began to seriously recover. Thus, we cannot infer a secular trend from our period of study. However, our finding

19 The correlation at a quarterly frequency (abstracting from seasonal variation) the correlation is 0.32 with a standard error of 0.06 . 
that the pace of the E-to-E flows remains low in the post-2001 period is consistent with the declining pattern of job and worker flows found in DFH.

There is also a pronounced seasonal cycle in the pattern of E-to-E flows. In our sample, E-to-E flows as a fraction of jobs are more common in the third quarter, with the second quarter also high for much of the period. On average over our sample period, the E-to-E rate, as a fraction of jobs, is $4.0 \%$ in the third quarter, compared to a low of $3.5 \%$ in the first quarter. Interestingly, the seasonal pattern is different as a fraction of separations, where the stand-out is the low rate at which separators move to new employers in the fourth quarter of the year. Not surprisingly, however, these patterns are not entirely uniform either across states or across industries. The seasonality of E-to-E flows raises many interesting questions and deserves further exploration. We leave such exploration for future work.

\section{The distribution of E-to-E flows}

We have documented that employer-to-employer flows are common, in the sense that the magnitude is large. We would also like to know how common such flows are in the sense of being experienced widely across workers and firms. In terms of the limited demographic characteristics available to us at this point, E-to-E flows are fairly widespread. Age is the major source of concentration, although education also plays some role. The difference across gender is minimal.

It has been well known from sources like the NLSY that turnover, including E-to-E rates, falls rapidly with age from the early post-schooling years through early middle age. Less was

known about E-to-E flows at older ages. Fallick and Fleischman found that E-to-E rates (relative to employment) were fairly stable from about the mid-40s on, despite an increase in separation rates that becomes quite steep around retirement ages. The LEHD data tell a somewhat different story. Figure 3a shows that E-to-E rates fall continuously with age before flattening out in the mid 60s. ${ }^{20}$ Figure $3 \mathrm{~b}$ shows that the fraction of separations that are E-to-E transitions, not surprisingly, falls rapidly in ages in the early 60s, as retirements presumably take up a large share of separations. 
Figure 4 shows that differences by education are not as pronounced. Relative to employment, E-to-E rates are lower for workers with more education. However, much of this simply reflects greater general turnover among less educated workers. When viewed relative to separations, E-to-E rates fall more gently as education rises. ${ }^{21}$

These demographic differences show that while E-to-E flows are quite widespread, some workers are more likely than others to change employers. But, of course, there is a great deal of heterogeneity not accounted for by the crude demographic characteristics we have available, and many workers change employers repeatedly. Table 4 examines to what extent frequent job changers dominate the overall rate of flows. It shows the frequency of E-to-E transitions (conditional on being employed) in the first quarter of 1997, broken down by the number of Eto-E transitions a person has made in the three-year period 1994-1996. Even among those who have made no E-to-E transitions during the 1994-1996 period, 2.6\% changed employers in 1997q1. Not surprisingly, however, the likelihood of an E-to-E transition (conditional on being employed) is higher for those who have made such a transition recently, and rises with the number of recent E-to-E transitions. For the most part, this is because workers who changed employers more frequently in the previous few years are more likely to separate in general from their current employers, but, as the right-most column shows, even as a fraction of separations Eto-E rates are higher for those who recently changed employers more often.

This pattern of "occurrence-dependence" is reflected in the concentration of E-to-E flows among workers. As shown in second panel of Table 4, about 4\% of E-to-E transitions in a threeyear period (1994-1996) are accounted for by the 1\% of workers who change employers most frequently (who happen to make at least 5 E-to-E transitions in the 1994-96 period). About 53\% percent of E-to-E flows are accounted for by the $25 \%$ of workers who have had more than one Eto-E flow over the period.

\footnotetext{
${ }^{20}$ Although the pattern at these older ages varies by state.

${ }^{21}$ The patterns by education vary by state, so even this qualitative results should not be taken as representative of the nation.
} 
Another side to this die is the way in which the rates of E-to-E flows vary by job tenure. Figure 5 shows that the fraction of workers who change employers is lower among workers with more tenure, in keeping with their overall lower rates of separation. But among those who do separate, there is not a straightforward relationship between tenure and the probability that the separation is an E-to-E transition. As a fraction of separations, higher-tenure workers (defined as those with their employer for more than two years) have similar E-to-E rates as low-tenure workers (defined as those with their employer less than one year), but lower E-to-E rates than medium-tenure workers (with their employers one to two years).

Similarly, some employers are more likely than others to be a source of E-to-E flows. The top panel of figure 6 divides the firms in our sample into five approximate quintiles, weighted by employment, according to the percentage of their average workforce that changes employer each quarter. In the middle quintile, firms with "average” E-to-E outflows see about $1.8 \%$ of their workforce change employers each quarter. But E-to-E flows are highly concentrated: The highest-EE quintile of employers accounts for nearly two-thirds of all E-to-E flows, while the bottom quintile accounts for almost none. As you can see from the right-most bar in each set, this concentration of E-to-E flows is not entirely attributable to the concentration of overall separations among firms. While there is some association between the two, the highest quintiles share of E-to-E flows exceeds its share of separations in general by 20 percentage points, while the lowest quintile, which sees almost no E-to-E flows, accounts for a little more than $10 \%$ of overall separations.

\section{Destination jobs}

To the extent that employer-changes are voluntary, we would expect workers to be more satisfied, on average, with their new jobs than with their old. One manifestation of this would be longer average tenures at the destination jobs than at the jobs of origin. Especially among young workers, who account for a disproportionately large share of E-to-E flows, aging and experience gained would also tend toward progressively more stable employment relationships, and so longer average tenure at the new jobs. The long temporal reach of the LEHD allows us to examine this question. We find that E-to-E flows do appear to move workers toward longer job 
tenures. Table 5 divides the employer-employee matches in our sample into three categories: those that last less than one year (short), those that last 1-2 years (medium), and those that last more than 2 years (long). ${ }^{22}$ Short jobs constitute a disproportionately large share of both the origins and the destinations of E-to-E flows. However, a larger proportion of E-to-E flows begin in short jobs than end there (53\% vs. 47\%), and a considerably larger share of E-to-E flows end in long jobs than begin there (25\% vs.19\%). One would also expect that workers voluntarily switching from relatively good job matches (i.e. longer tenure jobs) would also be, on average, more satisfied with their new job than those leaving worse matches. The high rate at which workers separating from longer tenured jobs move to another long job - 43\% of E-to-E flows involving separations from longer jobs are to another long job - suggests this is indeed the case.

Similarly, to the extent that employer changes are voluntary, we would expect them to be associated, on average, with increases in earnings. This appears to be the case as well. Figure 7 shows the median percent change in earnings for moves from one full-quarter employer to another. $^{23}$ For comparison, the figure also shows the median changes for full-quarter workers who do not separate from their employers. The median changes in earnings for employerchangers are large, and much larger than the median changes for non-separators. And for employer-changers, more than for non-separators, the earnings changes dropped off markedly when the labor market weakened moving toward the recession in 2001. Presumably a much larger proportion of the employer-changers during this period lost their jobs and faced earnings losses, or at least smaller gains, upon reemployment.

While the median worker who makes a job-to-job transition experiences an earning increase, there is substantial dispersion in the distribution of earnings changes. The earnings change from job-to-job transitions at the $25^{\text {th }}$ percentile is -14 percent and is 37 percent at the

22 Job tenure must be inferred from LEHD administrative data. We define job tenure here as the number of contiguous quarters of positive wages for a particular employer-employee match. Because tenure for separating jobs is censored on the left, and tenure for acceding jobs is censored on the right, we use a mid range year of the panel for our tenure analysis, where the maximum length of either a separating or acceding job is six years.

23 Because we do not have information on weeks or hours worked during the quarter, we confine our examination of earnings changes to full-quarter matches, in order to minimize the distorting influence of part-quarter jobs. Also, in order to preserve confidentiality, the "medians" shown here are really the average of the $48^{\text {th }}$ through $52^{\text {nd }}$ percentiles of earnings changes. 
$75^{\text {th }}$ percentiles. Like for the median, these patterns are procyclical with the $25^{\text {th }}$ percentile earnings change falling to -17 percent and the $75^{\text {th }}$ percentile falling to 33 percent in 2001 . The finding of substantial earnings reductions for a non-trivial fraction of job-to-job transitions suggests that not all such transitions are voluntary at least in the sense that they reflect transitions initiated solely by the worker in order to obtain earnings gains.

As seen in Figure 8, the earnings gains upon changing employers are greatest for younger workers. This is most marked for the youngest group of workers, the black line in Figure 8, where many of the workers may be moving from part-time in-school or summer jobs to career jobs. However, consistent with theories of job matching, it is also true for prime age groups. For the oldest group, the median earnings changes are often negative, perhaps reflecting bridge jobs with lower wage rates and reduced hours.

To put these patterns into context, it is instructive to compare job-to-job transitions with separations that do not yield a direct job-to-job transition. Such an analysis is beyond the scope of this paper, but in a companion paper (Fallick, Haltiwanger, and McEntarfer, 2007)we explore this comparison on a somewhat more restricted sample. There we find that the median earnings change for workers who experience a spell of joblessness between jobs is lower than for workers who experience a direct job-to-job transition. For example, for workers separating from firms without large displacement events, the median earnings change for workers who experience 2-3 quarters of joblesslessness is about -6 percent, compared to an 8 percent median increase for those who move directly to another job. For separations where a large displacement occurs, we find that workers with 2-3 quarters of joblessless have a median earnings change of about a -10 percent, compared to about a 3 percent change for those with direct job-to-job transitions. We also find considerable dispersion in the earnings changes for workers who experience a spell of joblessness, and that this dispersion increases with the length of the spell of joblessnessness. These comparisons help provide perspective on the consequences for earnings of job-to-job transitions as compared to transitions that involve joblessness, including, for example, those found in the job displacement literature (e.g., Jacobson, LaLonde and Sullivan 1993). 
Many E-to-E flows serve to reallocate workers across industries. The bar chart in Figure 9 illustrates the great extent of industry-switching among employer-changers. Among workers of all ages (the right-most set of bars), approximately 60\% of E-to-E movements are movements from one of the eleven NAICS super sectors to another, and only $16 \%$ of E-to-E transitions remain within the same most narrowly defined (6-digit) NAICS industry. The frequency of industry-switching varies by age, with younger workers naturally more likely to change sectors and least likely to remain within the same 6-digit industry. But even among the oldest category of workers, changing broad industries when changing employers is the norm.

The prevalence of industry-switching among E-to-E flows is thus widespread, but its extent does vary considerably by industry. The rows of Table 6 shows the percentage of E-to-E flows out of jobs in each of the eleven NAICS super sectors that remain in that super sector (the diagonal elements) or move to each other super sector. Even at this high level of industry aggregation, movements across industries are the rule. Remaining in the same supersector typically characterizes the plurality of E-to-E moves, but in only two cases does staying in the same super sector characterize even a bare majority.

Naturally, the most popular destinations for workers who switch industries via E-to-E movements differ from industry to industry. Thus, for example, workers leaving the professional \& business services super sector (which includes temporary help firms) are quite likely to move into manufacturing, while those leaving leisure \& hospitality are quite likely to move into trade, transportation \& utilities. These patterns are often not reciprocal. For example, many of the Eto-E flows out of information are into trade, transportation \& utilities, but few E-to-E flows go in the opposite direction.

The LEHD data allow us to examine these movements across industries in great detail. Figures 10 through 12 show the top ten most common destination industries for E-to-E flows from three particular detailed industries. Two of these industries - software publishing and temporary help services - grew over the period of our data, both in absolute numbers of jobs and in their share of jobs in the economy. The third industry - textile mills - shrank both in absolute numbers and in share. For software publishing and temporary help (figures 11 and 12), which 
are 6-digit industries, we defined destination industries at the 4-digit level. For textile mills (figure 10), which is a 3-digit industry, we defined destination industries at the 3-digit level.

The top-ten destinations comprise almost 2/3 of the E-to-E transitions from software publishing. The most common destination -- $27 \%$ of total flows - is other employers in software publishing. The remainder is dominated by other computer-related industries, mostly producers but also wholesalers and retailers. The one exception is employment services/temporary help (8\% of flows), where the employees may, in fact, be working at computer-related companies.

Not surprisingly, the destinations for E-to-E transitions from temporary help agencies are more diverse, with the top ten destinations comprising a little less than $1 / 3$ of the total. Within the top ten, the majority are other companies in employment services, with the remainder moving into a variety of manufacturing, food service, and other industries, presumably industries in which a large share of temporary help employees actually work.

For E-to-E transitions from textile mills, the top ten destinations comprise 38\% of transitions. Among these, other textile mills and establishments in the related apparel manufacturing industry make up the majority. Employment services (both temporary help and professional employer organizations) and restaurants round out the top ten.

We obviously do not want to draw conclusions from just a few industries, but these examples do suggest the importance of sector-related skills and of geographic proximity, as well as the substantial role of the temporary help industry in job mobility.

\section{Conclusion}

In this paper, we used longitudinal linked employer-employee data from the LEHD program at Census Bureau to measure and study employer-to-employer flows. These data provide a uniquely comprehensive source of information on workers and employers, while their quarterly nature present particular challenges to measurement of flows. We find that the pace of employer-to-employer flows is high - representing about 4 percent of employment and 30 percent of separations each quarter. The pace of employer-to-employer flows is highly 
procyclical. The cyclicality of employer-to-employer flows is a feature of the worker and job flows that should be taken into account in interpreting and modeling labor market dynamics.

The pace of employer-to-employer flows varies systematically across worker, job and employer characteristics. For workers, employer-to-employer flows as a fraction of employment and separations declines with age through the mid 60s and then flattens out -- the decline as a fraction of separations with age is especially rapid in the age range 50-65 when retirements presumably become a more important form of separation than employer-to-employer transitions. We find that less educated workers have a higher pace of employer-to-employer flows as a fraction of employment but there is no discernable pattern by education as a fraction of separations. The pattern by education reflects the higher overall rate of worker flows of less educated but conditional on a separation, education is not an important factor.

Our findings regarding job tenure and earnings dynamics suggest that for those workers moving directly to new jobs, the new jobs are generally better jobs, and that moving directly to a better job is easier during a boom than a bust. Tenure at new jobs is generally longer than at separating jobs. We find that on average workers who make employer-to-employer transitions see large increases in earnings. However, this pattern is highly procyclical. We also find a larger quarterly growth in earnings for workers making employer-to-employer transitions than for workers who remain in their same job.

There are rich patterns in terms of origin and destination of industries. We find somewhat surprisingly that a very large fraction of the workers making employer-to-employer transitions switch even broadly-defined industries. More than half of workers making an employer-to-employer transition switch NAICS super-sectors.

The focus of the current paper is primarily measurement and reporting of basic empirical patterns of employer-to-employer flows from a rich, new longitudinal employer-employee database at the U.S. Census Bureau. The magnitude and variation in employer-to-employer flows we have reported make clear that this measure of labor market dynamics should become a standard measure incorporated with measures of accessions, separations, job creation and job destruction. This measurement oriented paper is just the first step in the analysis of employer-to- 
employer flows. To understand the implications of employer-to-employer flows for our understanding of labor market dynamics, an obvious next step is to compare the outcomes for those workers who separate and immediately move to another job vs. those who separate and experience a spell of joblessness before finding another job. We know from the literature on job displacement (e.g., Jacobson, LaLonde and Sullivan (1992)) that workers who suffer a job loss from a business experiencing a mass layoff experience substantial earnings losses that are at least partly driven by spells of joblessness. It is clearly of interest to understand the relationship between the dynamics of the types of separations we have focused on in the current work and the type of separations associated with displacement. Exploring these issues is a high priority for future research. 


\section{References}

Abowd, John M., John Haltiwanger, and Julia I. Lane, 2004. “Integrated Longitudinal Employee-Employer Data for the United States.” American Economic Review Papers and Proceedings, 94(2): 224-229.

Abowd, John, Bryce Stephens, Lars Vilhuber, Fredrik Andersson, Kevin L. McKinney, Marc Roemer, and Simon Woodcock. "The LEHD Infrastructure Files and the Creation of the Quarterly Workforce Indicators” LEHD Technical Paper No. 2006-01.

Acs, Zolton J., Catherine Armington, and Alicia Robb, “Measures of Job Flow Dynamics in the U.S.”, CES 99-1, U.S. Bureau of the Census, January 1999.

Burgess, Simon, Julia I. Lane, and David Stevens, 2000. “Job flows, worker flows, and churning.” Journal of Labor Economics 18(3): 473-502.

Davis, Steven J., R. Jason Faberman, and John Haltiwanger. “The Flow Approach to Labor Markets: New Evidence and Micro-Macro Links.” Journal of Economic Perspectives, 20(3): 3-26.

Davis, Steven J., John C. Haltiwanger, and Scott Schuh, Job Creation and Destruction (Cambridge, MA: MIT Press, 1996).

Fallick, Bruce and Charles A. Fleischman, 2001, “The Importance of Employer-to-Employer Flows in the U.S. Labor Market,” Finance and Economics Discussion Series \#2001-18, Federal Reserve Board, Washington, DC.

Fallick, Bruce and Charles A. Fleischman, 2004, "Employer-to-Employer Flows in the U.S. Labor Market: The Complete Picture of Gross Worker Flows,” Finance and Economics Discussion Series \#2004-34, Federal Reserve Board, Washington, DC.

Fallick, Bruce, John Haltiwanger, and Erika McEntarfer, 2007. “Employment and Wage Consequences of Job Separation in the U.S.”, mimeo.

Golan, Amos, Julia Lane, and Erika McEntarfer, 2006. “The Dynamics of Worker Reallocation Within and Across Industries.” Economica (forthcoming).

Jacobson, Louis, Robert LaLonde and Daniel Sullivan, 1993 “Earnings Losses of Displaced Workers.” American Economic Review, vol. 83(4), pages 685-709. 
Table 1: Example of Quarterly Earnings Histories

\begin{tabular}{|c|c|c|c|c|c|}
\hline \multicolumn{2}{|c|}{$\begin{array}{l}\text { Person/Employer Match } \\
\text { (Job) }\end{array}$} & Q1 & Q2 & Q3 & Q4 \\
\hline Person 1 & Firm A & $\$ 0$ & $\$ 500$ & $\$ 0$ & $\$ 0$ \\
\hline Person 1 & Firm Q & $\$ 0$ & $\$ 1000$ & $\$ 0$ & $\$ 0$ \\
\hline Person 2 & Firm B & $\$ 2500$ & $\$ 1500$ & $\$ 0$ & $\$ 0$ \\
\hline Person 2 & Firm Z & $\$ 0$ & $\$ 750$ & $\$ 3000$ & $\$ 3000$ \\
\hline
\end{tabular}

Notes: all persons, firms, and wages in examples are fictionalized and do not reflect any individual's wage records.

Table 2: Employer-to-Employer Flow Rates By Employment and Separations

\begin{tabular}{|l|l|l|}
\hline Employer-to-Employer Flow Rate & $\begin{array}{l}\text { Consecutive- } \\
\text { Quarter E-to- } \\
\text { E Flows (EEb) }\end{array}$ & $\begin{array}{l}\text { Full- } \\
\text { Quarter E- } \\
\text { to-E Flows } \\
\text { (EEf) }\end{array}$ \\
\hline E-to-E flows/jobs & 0.0387 & 0.0220 \\
\hline Persons experiencing E-to-E/employment & 0.0410 & 0.0230 \\
\hline E-to-E flows/job separations & 0.2647 & 0.2020 \\
\hline Persons experiencing E-to-E/persons separating from jobs & 0.2727 & 0.2045 \\
\hline
\end{tabular}

Notes: Employer-to-employer flow rates are calculated as the ratio of the number of job flows (or person flows) of the flow type to the number of jobs (or separations) that have the same attachment criteria as the separating job in the E-to-E flow. Thus the denominator for EEb/separations is all jobs for which $s_{2 i j t}=1$, for EEf/separations it is all jobs for which $s_{3 i j t}=1$. The jobs denominator is EEb flow rates is all jobs for which $m_{i j t}=1$ and $m_{i j t-1}=1$. The jobs denominator for EEf flow rates is all jobs for which $m_{i j t}=$ 1 and $m_{i j t-1}=1$ and $m_{i j t-2}=1$. 
Table 3: Employer-to-Employer Flows: By Main and Secondary Jobs

\begin{tabular}{|l|l|}
\hline Description: & Rate: \\
\hline Proportion of workers with only a main job in a quarter & 0.9407 \\
\hline Proportion of workers with secondary jobs in a quarter & 0.0593 \\
\hline Separation rate from main jobs & 0.1345 \\
\hline Separation rate from secondary jobs & 0.3145 \\
\hline E-to-E flows/jobs: main job to main job flows only & 0.0393 \\
\hline E-to-E flows/jobs: secondary job flows only & 0.0288 \\
\hline Percentage of Flows: & \\
\hline Main job-to-Main Job & 0.9558 \\
\hline Main job-to-Secondary job & 0.0057 \\
\hline Secondary-to-Main job & 0.0102 \\
\hline Secondary-to-Secondary job & 0.0283 \\
\hline Percentage of Separations: & \\
\hline Separation from main job into new main job & 0.2899 \\
\hline Separation from main job into new secondary job & 0.0017 \\
\hline Separations from main job that do not involve a E-to-E flow & 0.7084 \\
\hline Separation from secondary job into new main job & 0.0219 \\
\hline Separation from secondary job into new secondary job & 0.0587 \\
\hline Separations from secondary jobs that do not involve a E-to-E flow & 0.9194 \\
\hline
\end{tabular}

Notes: All E-to-E flows are EEb flows. Separations from main jobs are defined as separations from jobs with positive earnings in $\mathrm{t}$ and $\mathrm{t}-1$ that have the greatest earnings weighted average earnings over the last four quarters (i.e. $\max \left[\left(\sum_{\mathrm{t}}^{\mathrm{t}}\right.\right.$ $\left.\left.{ }_{3} \mathrm{~W}_{\mathrm{ijt}}{ }^{2}\right) / 4\right]$ ). Accessions to main jobs are defined as accessions to jobs with positive earnings in $t$ and $t+1$ that have the greatest earnings weighted average earnings in the subsequent four quarters (i.e. $\left.\max \left[\left(\sum^{\mathrm{t}+3}{ }_{\mathrm{t}} \mathrm{W}_{\mathrm{ijt}}{ }^{2}\right) / 4\right]\right)$. 
Table 4: E-to-E Flow Rates Conditional on Flow History and Concentration of E-to-E Flows Among Highly-Mobile Workers

\begin{tabular}{|c|r|l|}
\hline & $\begin{array}{l}\text { Proportion of } \\
\text { workers in this } \\
\text { group having a } \\
\text { E-to-E flow in } \\
\text { 1997q1 }\end{array}$ & $\begin{array}{l}\text { Proportion of } \\
\text { separating workers } \\
\text { in this group } \\
\text { having a E-to-E } \\
\text { flow in 1997q1 }\end{array}$ \\
\hline $\begin{array}{c}\text { Number of E-to-E Flows in 3 years } \\
(1994-1996)\end{array}$ & 0.0265 & 0.2488 \\
\hline 0 & 0.0583 & 0.3514 \\
\hline 1 & 0.08398 & 0.3916 \\
\hline 2 & 0.1084 & 0.4185 \\
\hline 3 & 0.1452 & 0.4479 \\
\hline $4+$ & & 0.2285 \\
\hline $\begin{array}{c}\text { Number of Separations in 3 years } \\
(1994-1996)\end{array}$ & 0.0193 & 0.2891 \\
\hline 0 & 0.0365 & 0.3222 \\
\hline 1 & 0.0561 & 0.3516 \\
\hline 2 & 0.0759 & 0.3953 \\
\hline 3 & 0.1119 & \\
\hline $4+$ & & \\
\hline
\end{tabular}

Percent of Total E-to-E Flows During 1994q1-1996q4 Accounted for by the Top X\% of Persons Ranked by Number of E-to-E Flows During the Interval

\begin{tabular}{|l|l|}
\hline & \% of Total E-to-E Flows \\
\hline Top 1\% (5+ flows) & $4.13 \%$ \\
\hline Top 5\% (3+ flows) & $24.70 \%$ \\
\hline Top 25\% (2+ flows) & $53.46 \%$ \\
\hline
\end{tabular}


Table 5: Employer-to-Employer Flows By Job Length at Separating and Acceding Job: All EEb Flows in 1997 (Percent/Row Percent).

\begin{tabular}{|l|l|l|l|l|}
\hline \multicolumn{5}{|c|}{ Tenure at Acceding Job } \\
\hline $\begin{array}{l}\text { Tenure at } \\
\text { Separating Job }\end{array}$ & $\begin{array}{l}\text { Short Job } \\
\text { (2-3 quarters) }\end{array}$ & $\begin{array}{l}\text { Mid-Length } \\
\text { Job } \\
(1-2 \text { years })\end{array}$ & $\begin{array}{l}\text { Longer Job } \\
\text { (>2 years })\end{array}$ & $\begin{array}{l}\text { \% of all } \\
\text { E-to-E } \\
\text { flows }\end{array}$ \\
\hline $\begin{array}{l}\text { Short Job } \\
\text { (2-3 quarters) }\end{array}$ & $29.49 / 55.50$ & $14.35 / 27.01$ & $9.29 / 17.49$ & 53.13 \\
\hline $\begin{array}{l}\text { Mid-Length Job } \\
(1-2 \text { years })\end{array}$ & $11.94 / 49.74$ & $8.42 / 30.12$ & $7.59 / 27.15$ & 27.94 \\
\hline $\begin{array}{l}\text { Longer Job } \\
(>2 \text { years) }\end{array}$ & $5.51 / 29.12$ & $5.32 / 28.12$ & $8.09 / 42.76$ & 18.93 \\
\hline $\begin{array}{l}\text { \% of all E-to-E } \\
\text { flows }\end{array}$ & 46.94 & 28.09 & 24.97 & \\
\hline
\end{tabular}

Notes: Tenure at separating jobs is calculated using contiguous quarters of positive wages for this worker-employer match from t to the beginning of the time series (1991q1).

Tenure at acceding jobs is calculated using contiguous quarters of positive wages from $t$ to the end of the time series (2003q4). As tenure in our data is censored on both the right and on the left, we use a mid-range year of the panel for this analysis, where there are six years of data looking backwards as well as forwards. 


\section{Table 6: Origin/Destination Matrix of NAICS Super-Sector Transitions}

NAICS Super-Sector Transitions

All Employer to Employer (EEb) Transitions in 1997

A: Natural Resources \& Mining

B: Construction

C: Manufacturing

D: Trade, Transportation \& Utilities

E: Information

F: Finance Activities

G: Professional \& Business Services

H: Educational \& Health Services

I: Leisure \& Hospitality

J: Other Services (expt Public Admin)

K: Public Administration

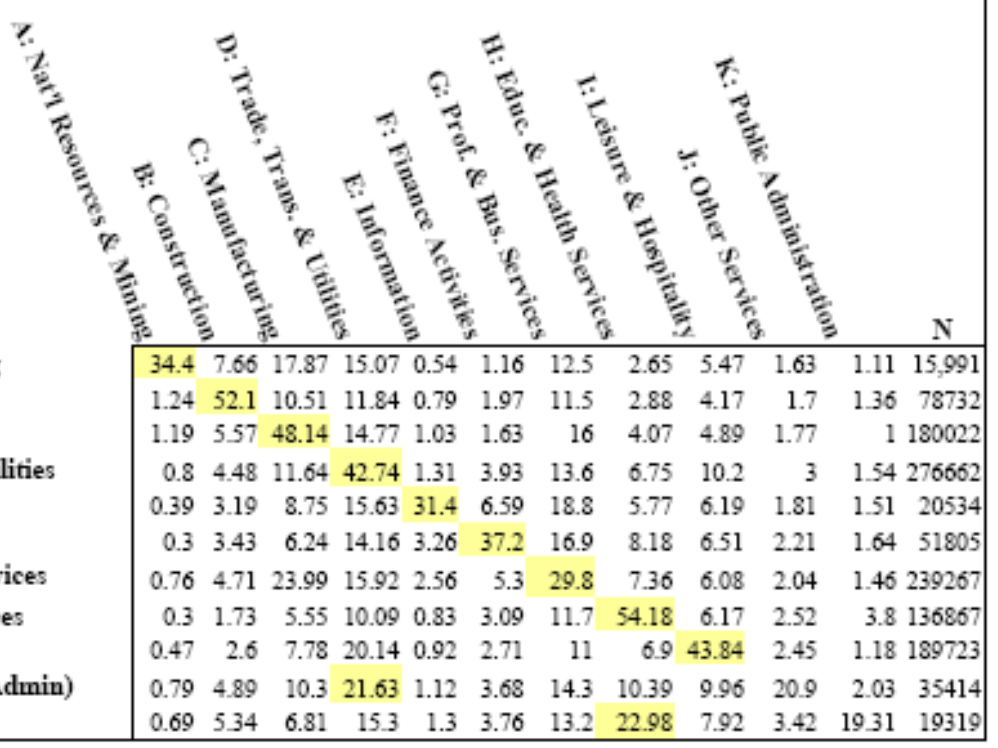

Indicates largest magnitude of flows 
Figure 1: Time Series of EEb flows: Fraction of beginning-of-quarter jobs that experience a flow to another employer by year: quarter.

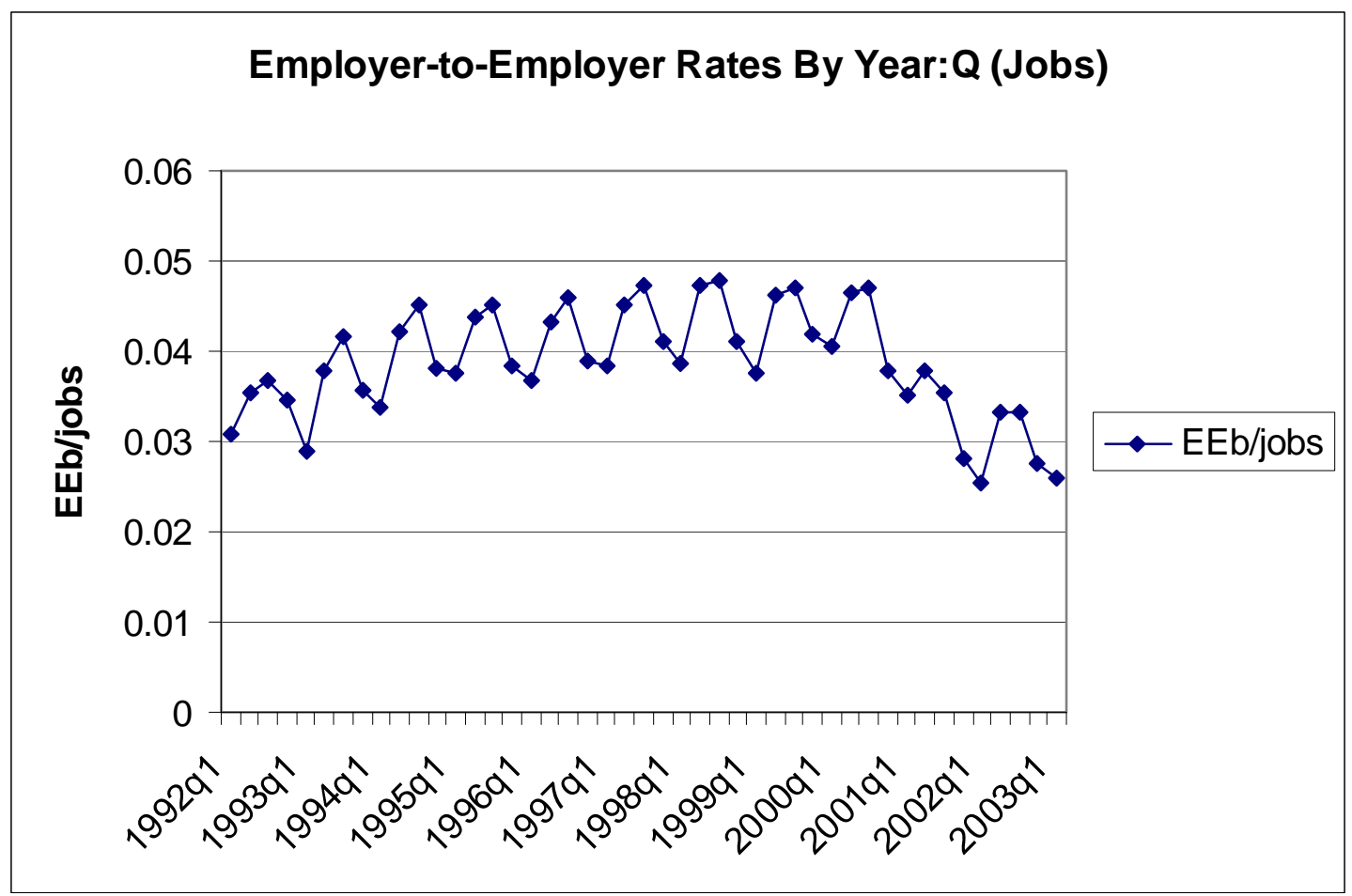


Figure 2: Time Series of EEb flows: Fraction of separations that experience a flow to another employer by year: quarter.

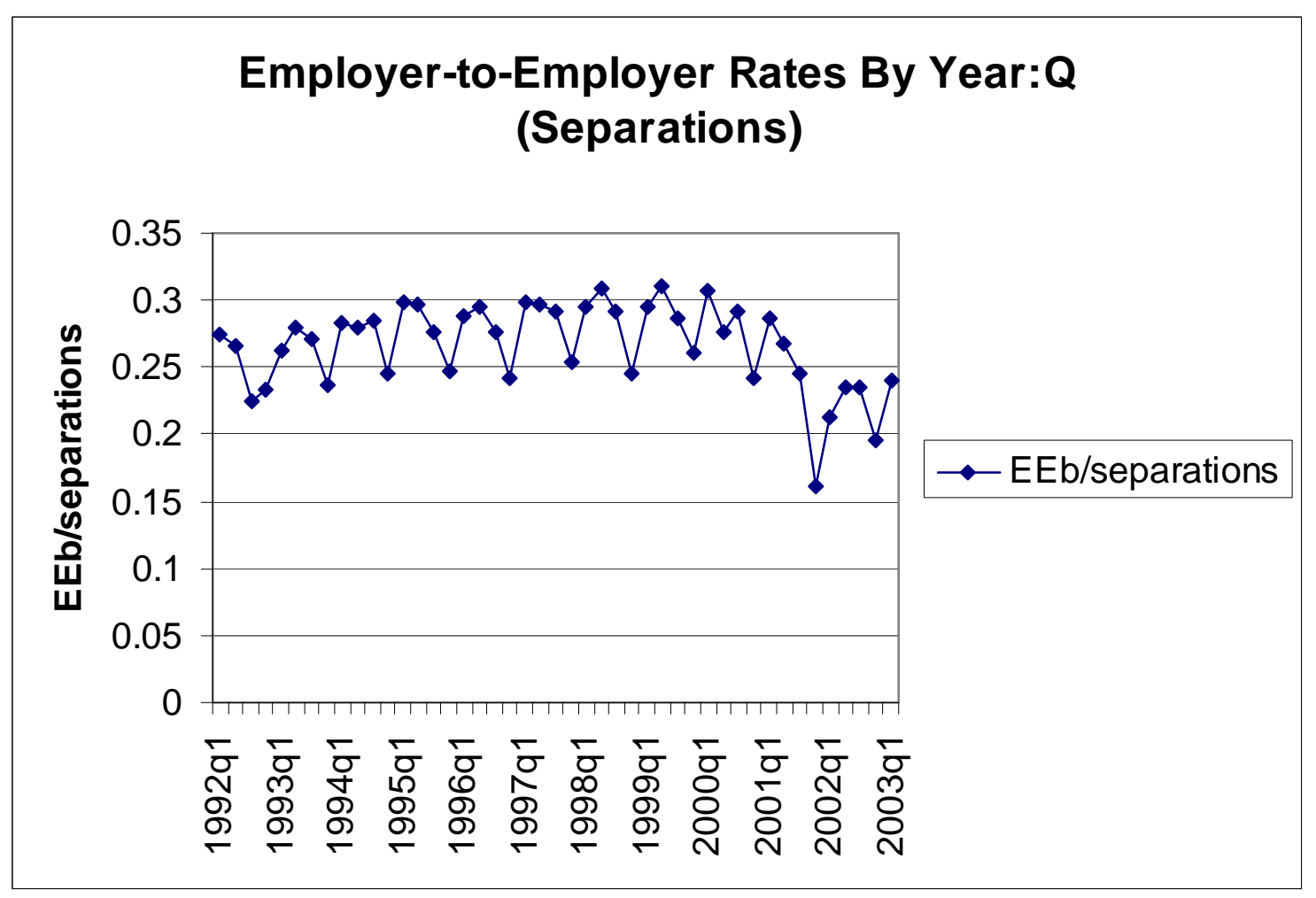


Figure 3: Employer-to-Employer (EEb) rates by age
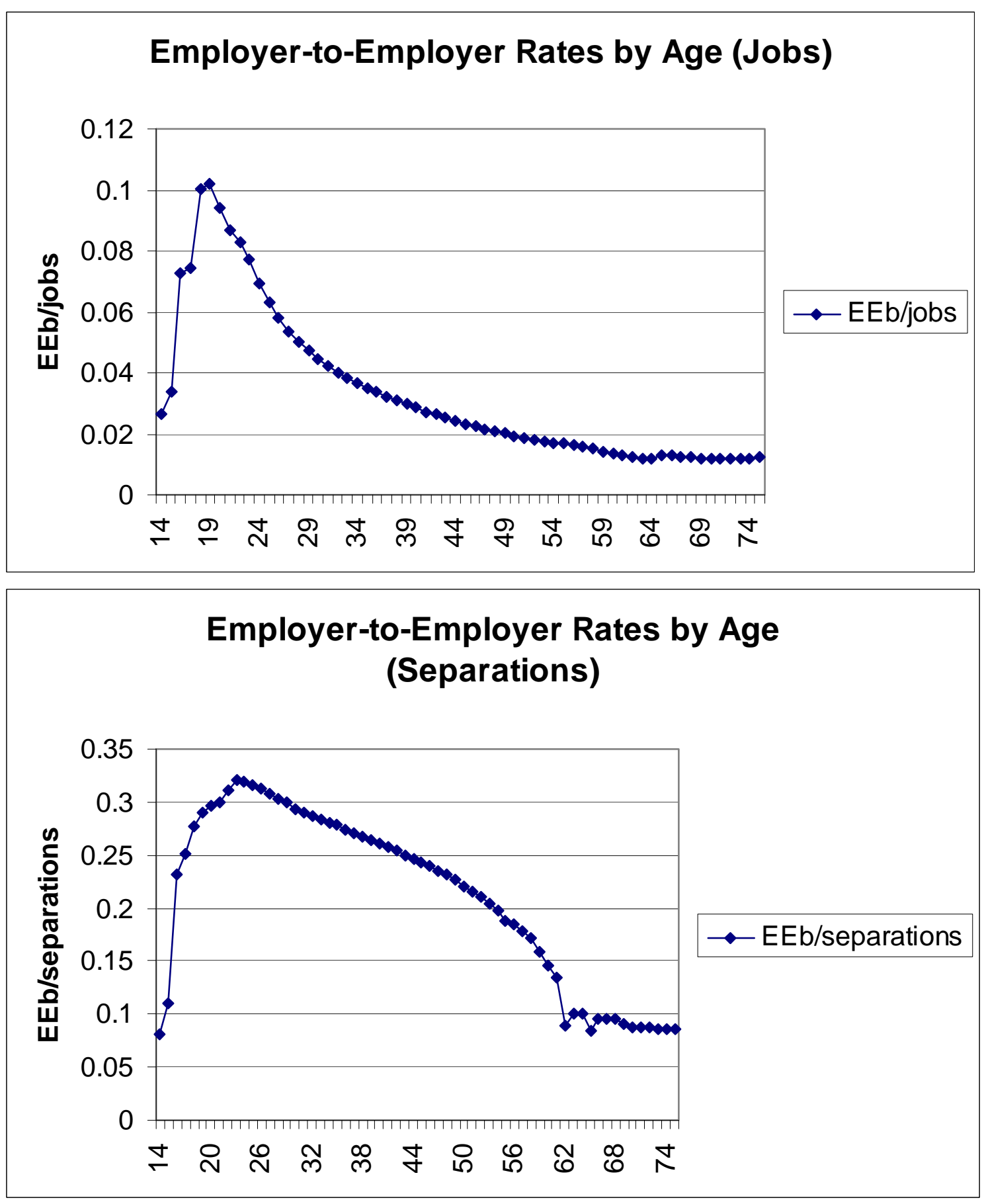
Figure 4: Employer-to-Employer (EEb) Rates By Education

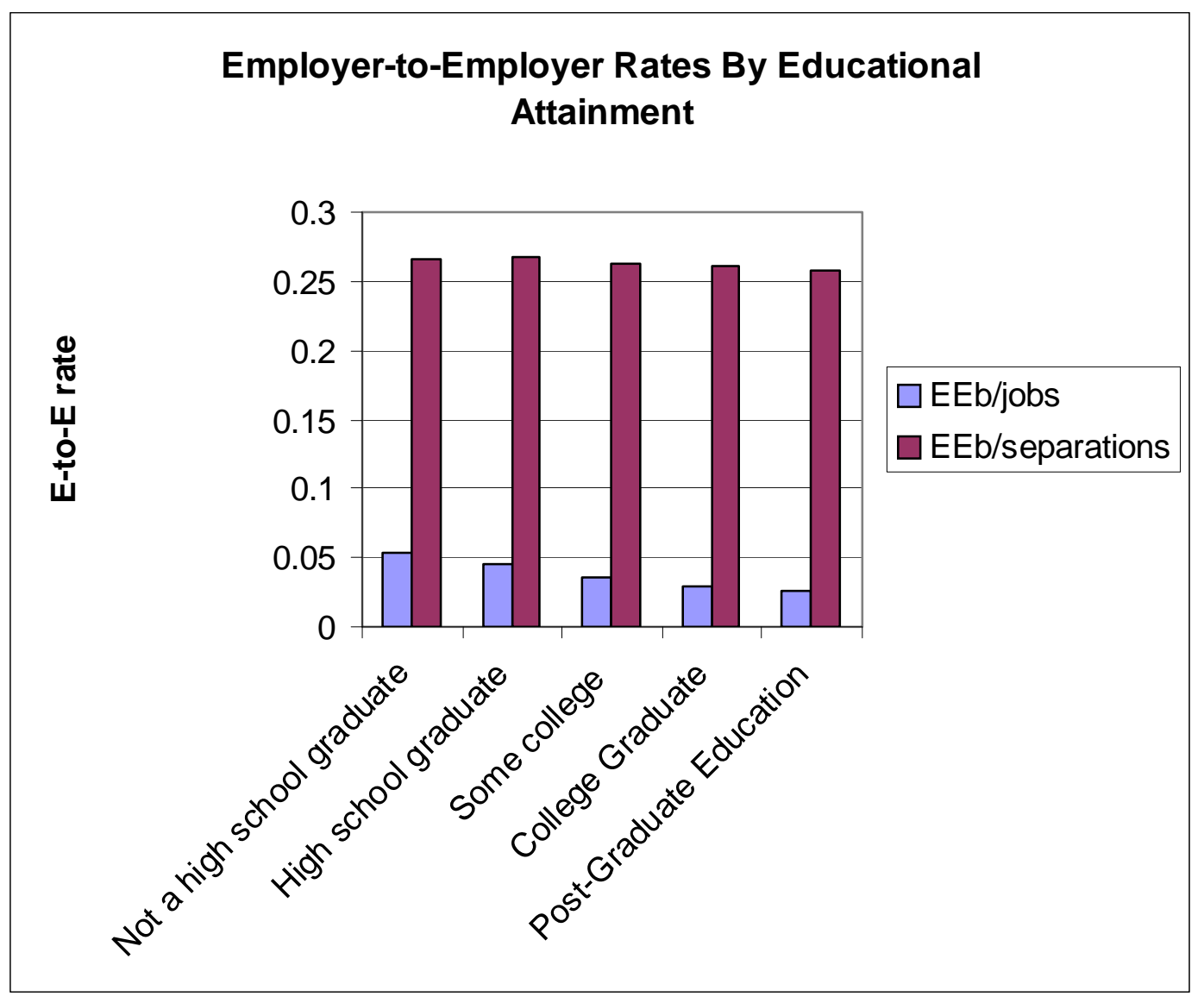


Figure 5: Employer-to-Employer Rates by Job Tenure
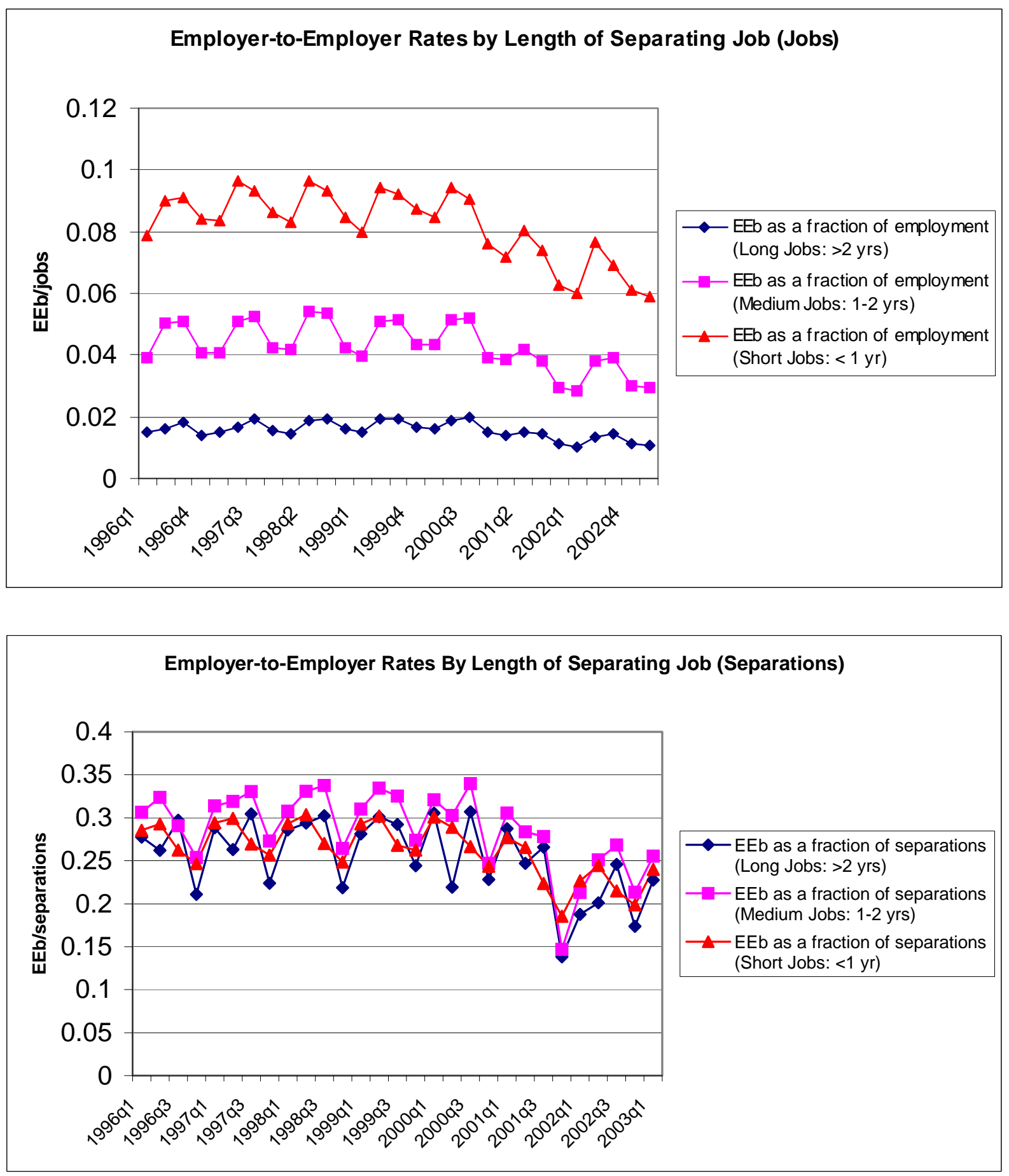
Figure 6: Concentration of E-to-E flows in firms with many flows.
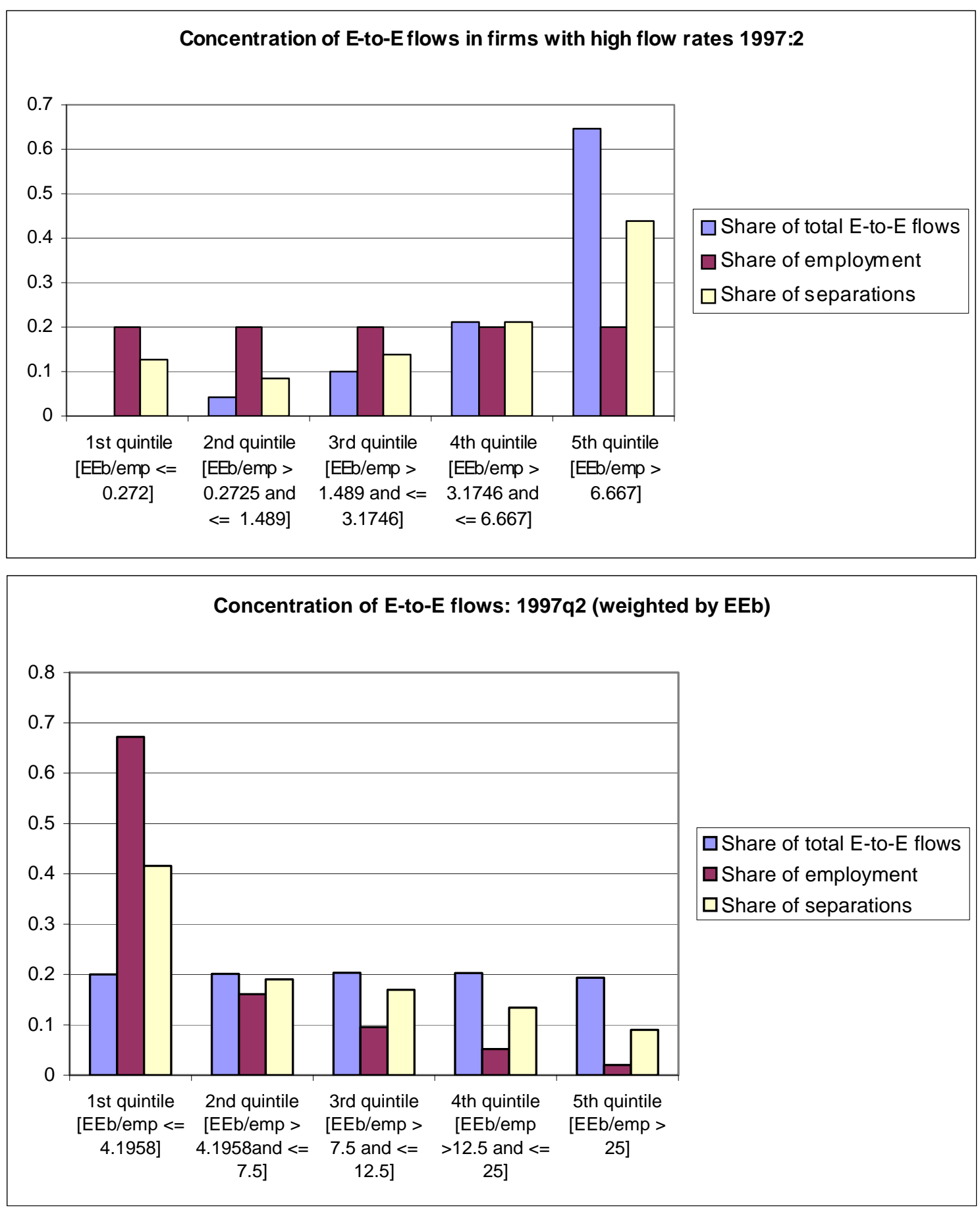
Figure 7: Time Series of Earnings Changes: Full-quarter E-to-E Flows

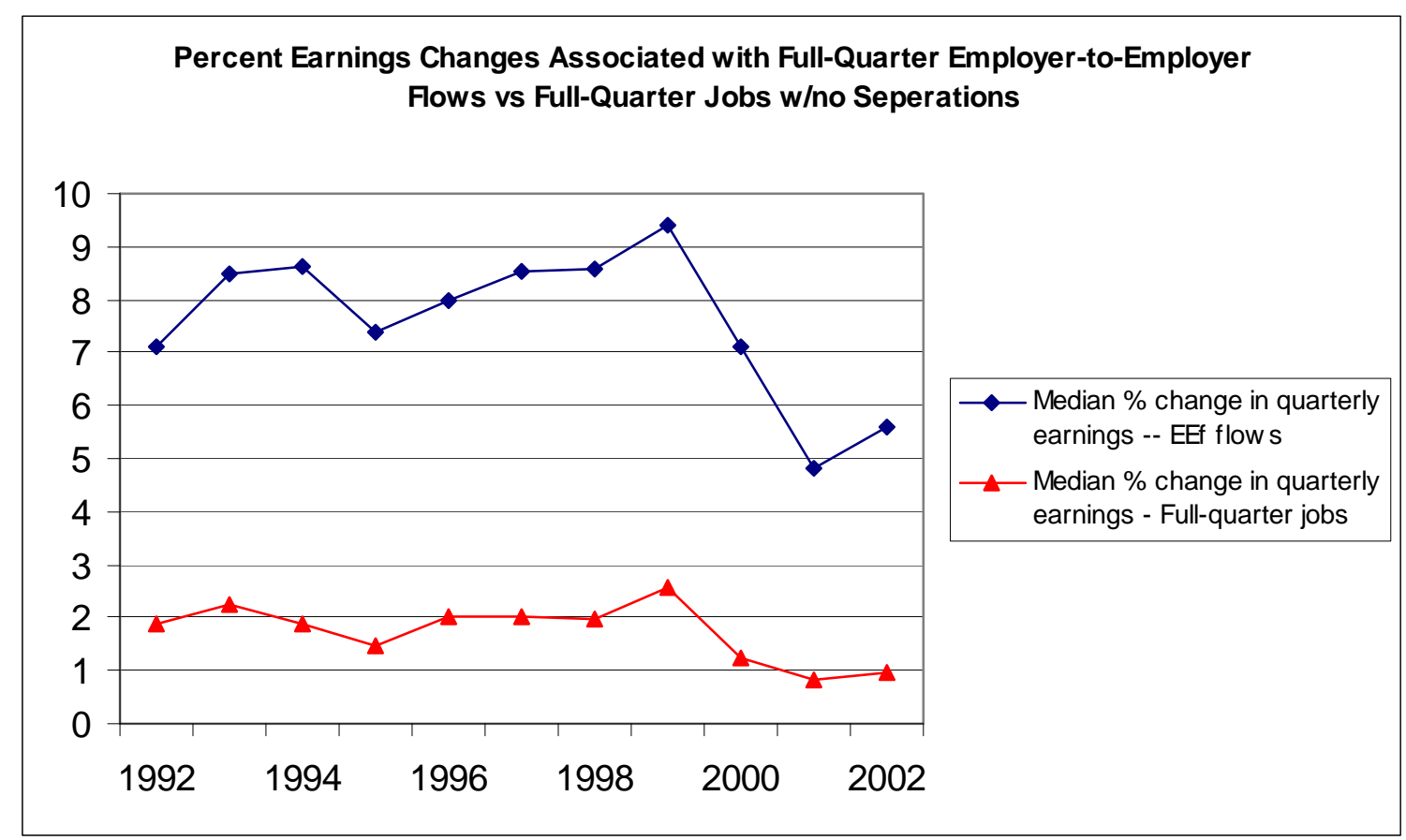

Note: All medians are fuzzed, equal to the average of the $48^{\text {th }}, 49^{\text {th }}, 50^{\text {th }}, 51^{\text {st }}, 52^{\text {nd }}$ percentiles. All earnings are real 2001 dollars. Full-quarter E-to-E flows are used as they contain a fullquarter of earnings before and after the flow. Full-quarter continuing jobs are defined at those jobs that are full-quarter in $\mathrm{t}-1$ and in $\mathrm{t}+1$. 
Figure 8: Time Series of Earnings Changes: EEf flows by Age Group
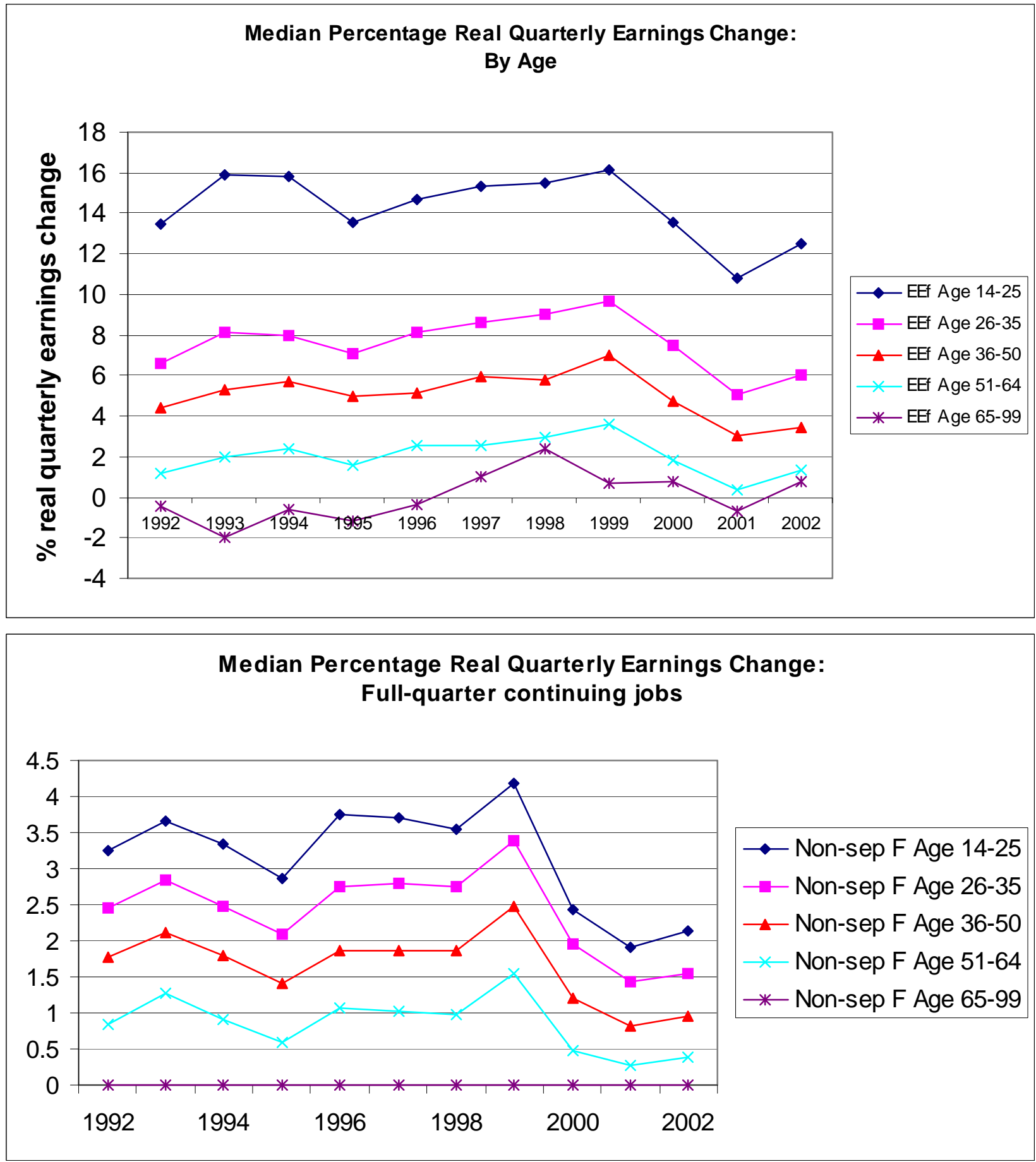

Note: All medians are fuzzed, equal to the average of the $48^{\text {th }}, 49^{\text {th }}, 50^{\text {th }}, 51^{\text {st }}, 52^{\text {nd }}$ percentiles. All earnings are real 2001 dollars. Full-quarter E-to-E flows are used as they contain a fullquarter of earnings before and after the flow. Full-quarter continuing jobs are defined at those jobs that are full-quarter in $\mathrm{t}-1$ and in $\mathrm{t}+1$. 
Figure 9: Rates of Industry Change By Age Group

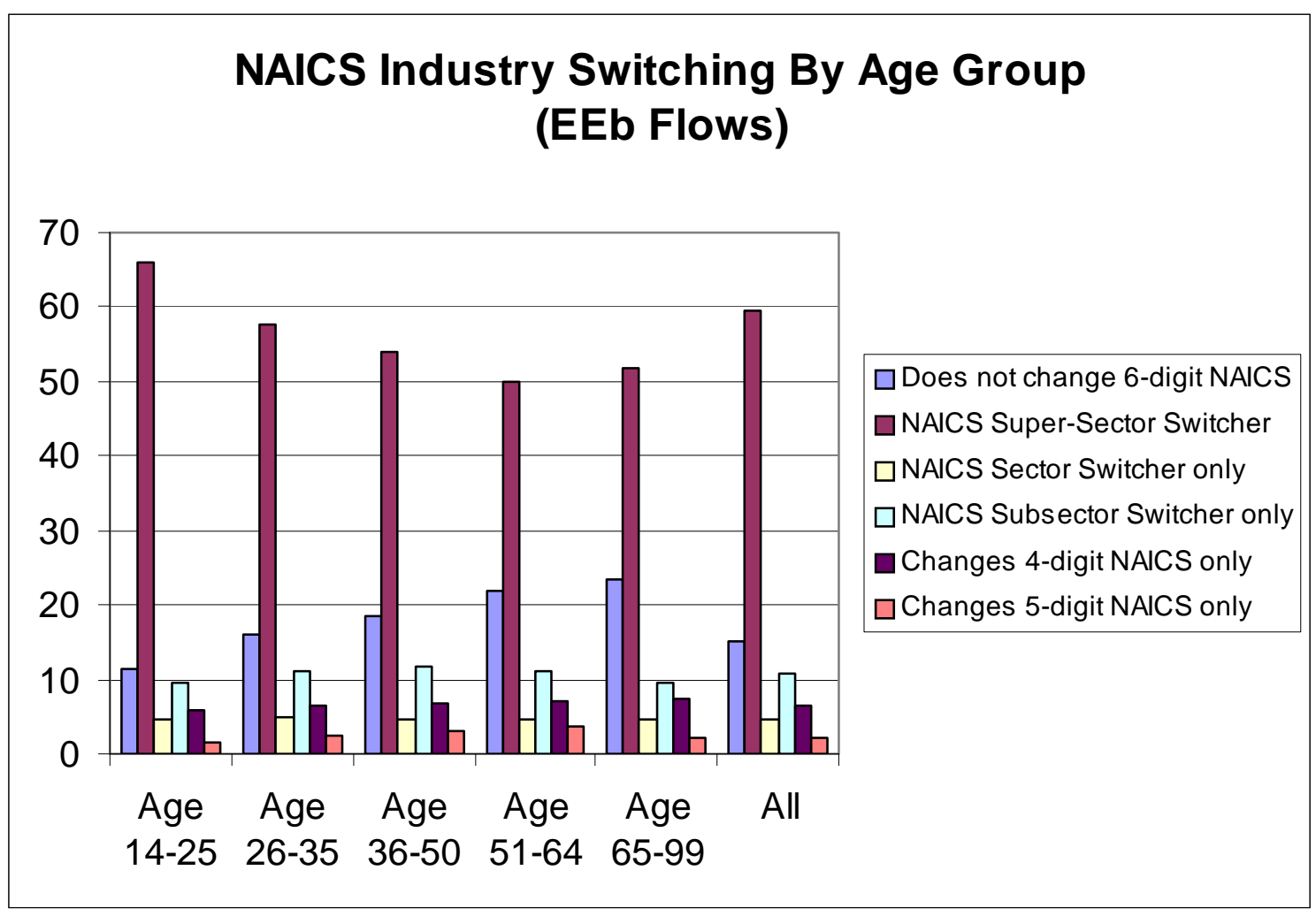


Figure 10: Top 10 Destination NAICS, Textile Mills

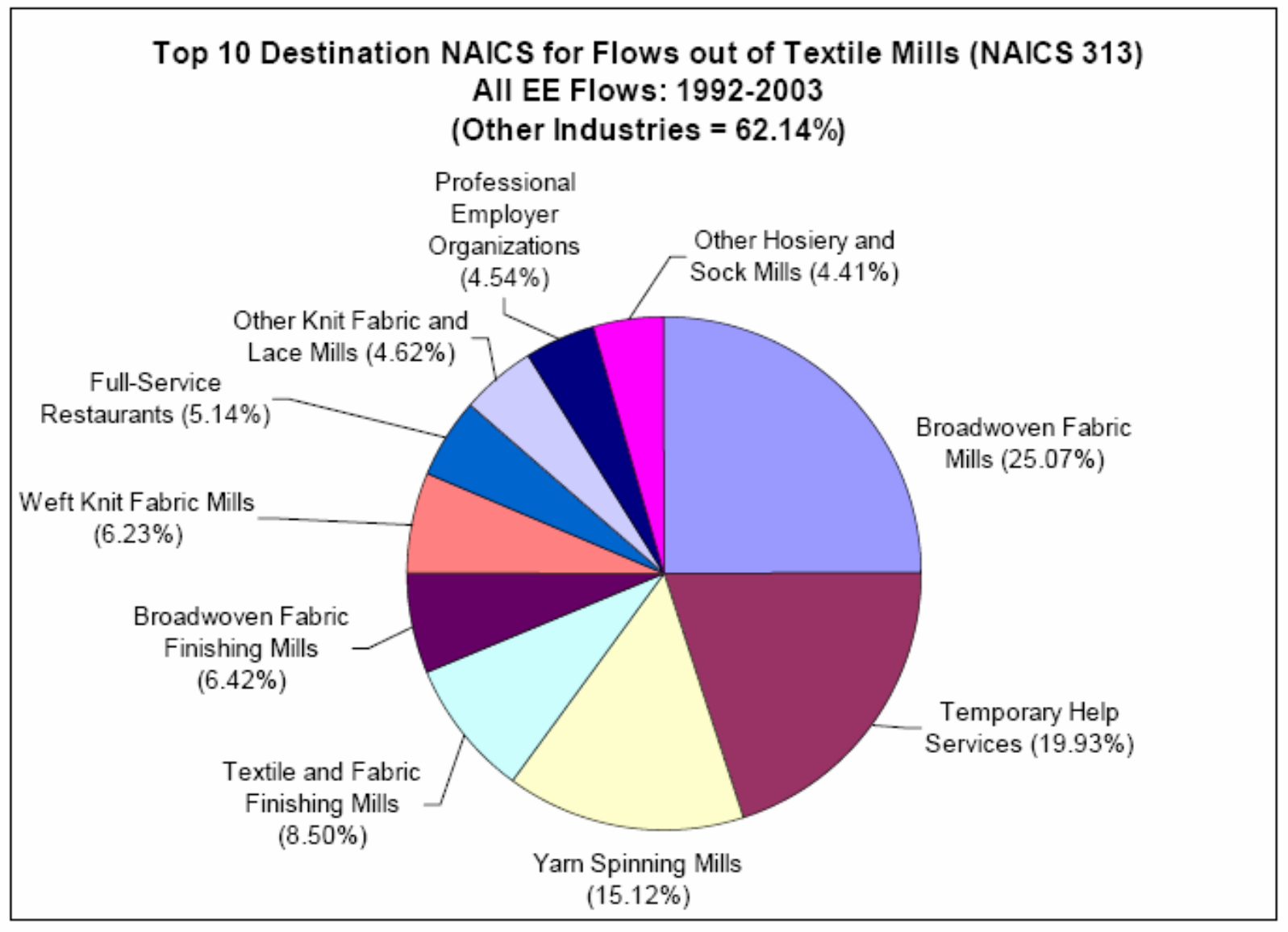


Figure 11: Top 10 Destination NAICS, Workers in Software Publishing

\section{Top 10 Destination NAICS for Workers in Software Publishing} (NAICS 5112)

EEb flows: 1992-2003, $\mathrm{N}=10,027$

(other industries $=39 \%$ )

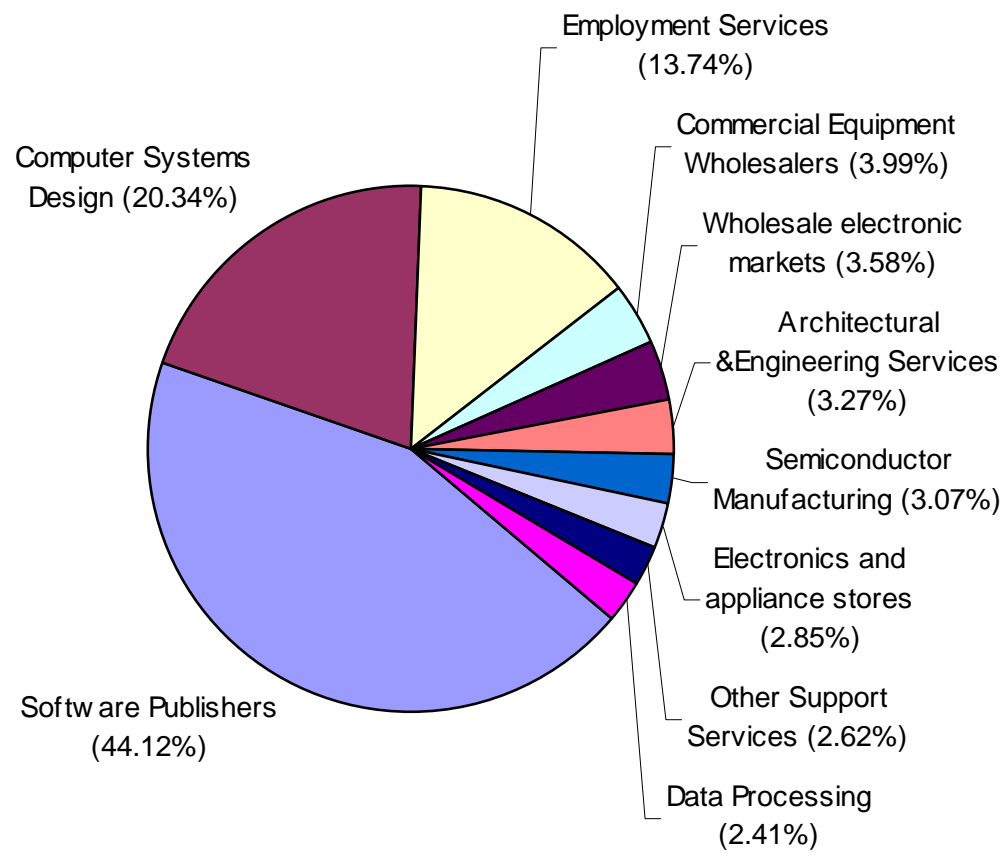




\section{Figure 12: Top 10 Destination NAICS, Temp Help}

Top 10 Destination NAICS for Workers in Temporary Services (NAICS 56132) All Employer-to-Employer Flows in sample with at least 2 quarters job attachment: 1992-2003 (Other industries $=68.6 \%$ )

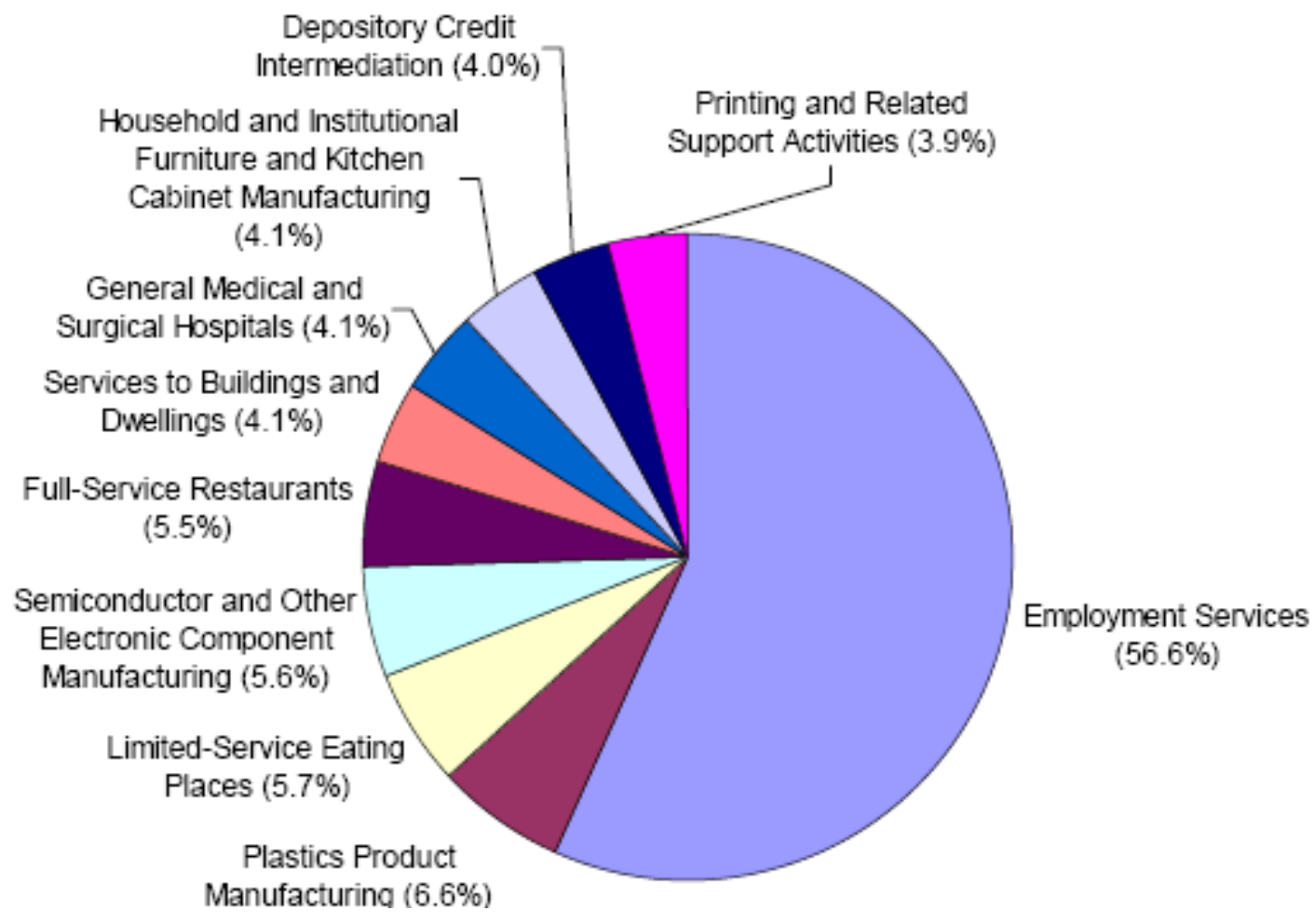

